\title{
LA LIBERTAD DE INVESTIGACIÓN CIENTÍFICA. PANORAMA DE SU SITUACIÓN EN EL CONSTITUCIONALISMO COMPARADO Y EN EL DERECHO INTERNACIONAL
}

\author{
FREEDOM OF SCIENTIFIC RESEARCH. AN OVERVIEW ON THE \\ SITUATION IN THE COMPARATIVE CONSTITUTIONAL AND \\ INTERNACIONAL LAW
}

\section{Marcela Ahumada Canabes*}

\begin{abstract}
RESUMEN: El presente trabajo tiene por objeto hacer una breve exposición sobre algunas de las particularidades de la libertad de investigación científica, para posteriormente revisar el panorama de la situación de este derecho humano en el Derecho constitucional comparado y en diversos instrumentos internacionales, y finalmente establecer el marco jurídico que tiene actualmente en nuestro ordenamiento jurídico.
\end{abstract}

Palabras clave: Libertad de Investigación Científica, Derechos Humanos, Protección Constitucional e Internacional.

ABSTRACT: The objective of this work is to do a brief description about special features of Freedom of Scientific Research, and then to check an overview on the treatment that it receives in the Comparative Constitutional Law and the way in which this human right has been recognized by some international instruments, and finally his legal framework in the Chilean Legal System.

Key words: Freedom of Scientific Research, Human Rights, Constitutional and International Protection.

\section{INTRODUCCIÓN}

En los últimos años, dos iniciativas legislativas han tenido por finalidad incorporar la libertad de investigación científica al catálogo de derechos de nuestra Carta Fundamental, ninguna de las cuales prosperó. El año 2001, durante la discusión del proyecto de ley sobre la libertad de creación artística, se propuso agregarla también al artículo $19 \mathrm{~N}^{\circ} 25$ de la Constitución Política de la República. Poco después, el año 2005, se presentó un proyecto de reforma constitucional con el objeto de contemplar, junto a la ya incorporada libertad de crear y difundir las artes, "la de desarrollar la investigación científica y difundir sus resultados", iniciativa que terminó archivada ${ }^{1}$.

\footnotetext{
* Profesora de Derecho Constitucional, Universidad Santo Tomás (Sede Viña del Mar). Correo electrónico: mahumadacan@yahoo.es.

Licenciada en Ciencias Jurídicas, Universidad de Valparaíso; Magíster en Derecho Público, con mención en Derecho Constitucional, Pontificia Universidad Católica de Chile; Doctora en Derecho, Universidad Carlos III de Madrid.

${ }^{1}$ Ambos intentos tienen el mismo origen. El primero corresponde a indicación formulada por el senador Augusto Parra Muñoz, en la Sesión 40 de la legislatura 343a, de 2 de mayo de 2001, que fue desechada. Historia
} 
La cuestión sobre el reconocimiento explícito de la libertad de investigación científica también fue objeto de debate en la génesis de la Constitución de 1980. Según quedó registrado en las Actas Oficiales de la Comisión de Estudio de la Nueva Constitución Política de la República, los comisionados tuvieron a la vista diversas disposiciones contenidas en textos constitucionales extranjeros y declaraciones internacionales de derechos humanos que la reconocen, debatiendo sobre ella al analizar el derecho a la educación y la libertad de enseñanza, aunque finalmente se estimó que no formaba parte de estos derechos ${ }^{2}$.

Los intentos de incorporar la libertad de investigación científica a la Carta Fundamental, así como el objeto del presente trabajo, no tienen por finalidad abogar por un derecho nuevo, sino que se refieren a la necesidad de consagrar explícitamente un derecho que, hasta ahora, ha estado implícitamente comprendido y amparado por la libertad de expresión.

En las últimas décadas este derecho ha recobrado importancia debido principalmente al avance experimentado por algunas ciencias, como la biomedicina, la genética y la genómica, y a la necesidad de establecer nuevos límites a su ejercicio.

Históricamente, los orígenes de la libertad de investigación científica, al igual que el de otros derechos, se remontan al renacimiento, período denominado también tránsito a la modernidad, momento en el que aparecen las primeras reivindicaciones y al que, entre otros fenómenos, contribuye el nacimiento de la ciencia moderna ${ }^{3}$. El ser humano, consciente de sus facultades, comienza a reclamar su autonomía y algunos incipientes "derechos", que posteriormente serán plasmados en los primeros textos positivos. Reivindica, entre otros, su "libertad filosófica y científica [...]. No le importa tanto el tenor de las conclusiones a las que llegue en la investigación como el hecho de que no hayan existido autoridades dogmáticas ni imposiciones en el seno de la misma" ${ }^{4}$. Se reivindica la "libertad de la ciencia", la "libertad de filosofar" o el "libre filosofar" ${ }^{5}$ locuciones que aluden a la "exigencia de liberar el conocimiento científico del mundo y del hombre" 6 , en el sentido de eliminar los límites heterónomos e incluso los autoimpuestos.

En un principio, la reivindicación de la libertad de investigación científica va unida a la de las libertades de pensamiento y de la manifestación o expresión del mismo, derechos

de la ley $\mathrm{N}^{\circ} 19.742$, reforma constitucional que elimina la censura cinematográfica, sustituyéndola por un sistema de calificación y que consagra la libertad de creación artística. Vid., especialmente, pp. 184-186 y 243-244. Disponible en http://www.leychile.cl/Navegar?idNorma=188827\&buscar=19742. El mismo parlamentario presentó, tiempo después, un proyecto de reforma constitucional, ingresado al Senado con fecha 16 de junio de 2005, Boletín 3895-07. http://sil.congreso.cl/. Ambos consultados 25 de enero 2011. Estas propuestas coinciden con la consagración conjunta que suelen tener estas libertades.

${ }^{2}$ Actas de la Comisión de Estudios de la Nueva Constitución, Tomo IV, Sesión № 135, de 3 de julio de 1975, pp. 497, 498, 500 y 501; Sesión No 137, de 10 de julio de 1975: pp. 537-545, 561 y 569-572; Sesión 139, de 17 de julio de 1975: p. 569; Sesión $N^{\circ} 140$, de 22 de julio de 1975: pp. 588, 590 a 594 y 623, Sesión $N^{\circ} 141$, de 24 de julio de 1975, pp. 616, 621,623. Disponible en http://www.bcn.cl/lc/cpolitica/actas_oficiales-r (Consultado en octubre de 2011).

${ }^{3}$ Peces-Barba (1999) pp. 127, 133 y 134.

${ }^{4}$ Ansuátegui (1994) p. 102.

${ }^{5}$ GaLileo Galilei se refería al "libre filosofar sobre las cosas del mundo y la naturaleza". GaLilei (1994) pp. 74 y 120. Lo que se reivindica, en ese entonces, es la independencia de la verdad científica respecto de las Escrituras y del principio de autoridad, que imponía las opiniones aristotélicas como verdad indiscutible.

${ }^{6}$ GARÍn (1982) p. 149. 
que son, en definitiva, los que tendrán consagración positiva en las primeras declaraciones de derechos y los que ampararán la actividad científica mientras no se contemple un derecho específico.

Esa protección implícita se explica por los fundamentos comunes de la libertad de investigación científica con esas otras libertades. De hecho, ellos son difíciles de diferenciar con precisión. La vinculación de la libertad de investigación científica con la libertad de expresión se debe a que esta última permite "dar a conocer sin trabas los resultados a que arribe" ". Pero la libertad de investigación científica es mucho más que la difusión de sus resultados, pues faculta al científico para, por ejemplo, elegir el objeto de estudio; escoger el tema, aspecto o tópico a investigar, el área del conocimiento a explorar o lo que es igual, elegir una línea de investigación, según sus intereses, inquietudes y motivaciones particulares. También comprende la búsqueda y acceso a la información, al conocimiento existente y disponible, sin trabas de ninguna especie ${ }^{8}$. Asimismo, pueden identificarse otras conductas propias de esta libertad como el acopio de datos, la formulación de hipótesis, su comprobación, la elaboración de teorías, la elección del método científico y la plasmación de los resultados de la actividad investigativa.

Aunque la elección de las líneas de investigación es también una facultad en la que el titular del derecho obra con completa autonomía, en algunos casos, la elección puede no ser tan libre. Ello sucede, por ejemplo, si dichas líneas son determinadas por quién financia o subvenciona la investigación. Así, el Estado podría orientar o influir en la elección, mediante la asignación de becas o a través de la distribución de fondos públicos, privilegiando algunos proyectos en desmedro de otros? .

Si bien la libertad de investigación científica nació estrechamente vinculada a la libertad de expresión, como ha ocurrido con otros derechos, paulatinamente se fue desvinculando de ella y adquiriendo autonomía, lo que debería reflejarse en las normas jurídicas.

La libertad de investigación científica tiene también una identificación terminológica y conceptual con la libertad de cátedra ${ }^{10}$, con la cual comparte el ámbito espacial en el que ambas suelen ejercerse. Es lo que ocurre en el caso de la investigación llevada a cabo en la universidad, donde la búsqueda del conocimiento y su transmisión van unidos. Pero, en su evolución, la ciencia se ha expandido y hoy en día no toda la investigación se desarrolla en la universidad, sino también en centros privados y en la industria.

\footnotetext{
${ }^{7}$ Mayorga (1990) p. 95.

${ }^{8} \mathrm{La}$ anterior aseveración es in perjuicio de que el libre acceso a las fuentes puede verse obstaculizado en la práctica. Sería el caso, por ejemplo, de los historiadores que encuentren dificultades para acceder a los archivos estatales o que lo ven condicionado a determinados resultados de la investigación. El ejemplo lo he tomado de EsER (1987), p. 579 que también alude a la legislación protectora de bases de datos, que puede ser utilizada para bloquear las investigaciones no queridas por las estructuras de poder.

9 También podría hacerlo la empresa privada, caso en el que las prioridades las fijaría el mercado o las ventajas económicas que se adviertan en un determinado objeto de estudio. Piénsese en la escasa investigación sobre enfermedades raras o que afectan a países del tercer mundo.

${ }^{10}$ Ambos derechos reciben la denominación de libertad de la ciencia o libertad científica Lucas Verdú (1981) pp. 340-341; CARro (1977) pp. 211-227.
} 
En nuestra Carta Fundamental, aunque la libertad de investigación científica no tiene consagración explícita, puede considerarse garantizada por su presencia implícita ${ }^{11}$ en el artículo $19 \mathrm{~N}^{\circ} 12$, que consagra la libertad de emitir opinión y la de informar, esto es, como una forma especial de ejercicio de la libertad de expresión ${ }^{12}$.

Pero la protección que puede brindar el artículo $19 \mathrm{~N}^{\circ} 12$ es hoy insuficiente, siendo deseable que la Constitución la contemple de manera explícita. La libertad de expresión ampara claramente la difusión de los resultados de la investigación científica, pero difícilmente puede proteger algunas actividades previas al discurso científico, como lo es, por ejemplo, la experimentación, actividad que en los siglos XX y XXI ha generado bastantes conflictos éticos y una gran cantidad de normas ${ }^{13}$.

Aunque en nuestro ordenamiento jurídico no se ha recurridos a los estrados judiciales para la solución de un eventual conflicto en que haya estado involucrada la libertad de investigación científica, su protección constitucional solo podría invocarse de manera indirecta, esto es, a través de derechos protegidos expresamente y además amparados por la acción constitucional de protección ${ }^{14}$ o por la vía del artículo $5^{\circ}$, inciso $2^{\circ}$, de la Constitución Política de la República y los diversos instrumentos internacionales que, como veremos, se refieren a ella ${ }^{15}$.

El estudio de esta libertad no es una cuestión desconocida en el Derecho comparado ${ }^{16}$, solo algunos autores del ámbito nacional han reparado que este derecho es uno de los tópicos a considerar en futuras reformas constitucionales ${ }^{17}$.

El propósito de este trabajo es hacer una breve alusión a las particularidades de la libertad de investigación científica, poniendo especial énfasis en aquellas que la distinguen de la libertad de expresión, para posteriormente efectuar una panorámica sobre el estado de situación de este derecho en el constitucionalismo comparado y en el Derecho internacional de los derechos humanos, y finalmente revisar sucintamente la regulación de la libertad de investigación científica en nuestro ordenamiento jurídico.

Parto de la premisa que la libertad de investigación científica es un derecho humano complejo, que comprende diversas facultades ${ }^{18}$, que se articulan en tres grandes dimensiones, esto es, una dimensión negativa, de autonomía o de defensa; una dimensión prestacio-

\footnotetext{
${ }^{11}$ La categoría de "derechos implícitos" tiene sustento en la STC Rol N 634, de 9 de agosto de 2007, considerando noveno, a propósito del derecho a la información.

12 Verdugo, Nogueira y Pfeifer (2002) p. 260. Ángela Vivanco, por su parte, se refiere incidentalmente al "derecho a la investigación" de los científicos al tratar el derecho a la vida, la manipulación genética y la clonación, pero sin vincularlo con las aludidas libertades de pensamiento y de expresión. Vivanco (2006) p. 276.

${ }^{13} \mathrm{La}$ experimentación con animales, la experimentación con seres humanos, con menores de edad y personas con capacidad disminuida; con células humanas.

${ }^{14}$ Navarro Beltrán (2009), pp. 141-154. El autor se refiere a la forma en que ha operado la protección constitucional indirecta, sin referirse a la libertad que aquí nos ocupa,

${ }^{15}$ Formaría parte de lo que autores como Humberto Nogueira denominan "el bloque constitucional de derechos fundamentales". Nogueira (2007) especialmente pp. 42 y ss.

${ }^{16}$ Véase, verbigracia, Pelayo (2002); Ruiz Vadillo (1986) pp. 3.645 y ss.; Peces-Barba (1994) pp. 317-335; Gómez (2007) pp. 1-52; Esteve Pardo (2008) pp. 1613-1633.

17 ZÚNiga (2005) p. 565.

${ }^{18}$ Cuando se trata de un derecho fundamental con consagración expresa en una Constitución, se habla, en palabras de Alexy, de un haz de diversas posiciones iusfundamentales ensambladas en un derecho como un todo.
} 
nal y una dimensión colectiva. La primera, comprende los elementos característicos de este derecho, los rasgos originarios e individualistas que la identifican. La segunda, se refiere a las actuaciones positivas de los poderes públicos a favor del ejercicio del derecho ${ }^{19}$, a la promoción y "predisposición de medios, instrumentos y recursos dirigidos a asegurar la plena expansión y desarrollo del espacio de autonomía individual en que este derecho consiste" 20 . Como muchos otros, este derecho no se agota con la mera abstención de los poderes públicos, sino que requiere de la realización de ciertas obligaciones prestacionales del Estado, tendentes a garantizar que el derecho pueda ser efectivamente ejercido por su titular ${ }^{21}$. Ello redundará en la dimensión colectiva o social que corresponde, en mi opinión, al denominado "derecho a gozar de los beneficios de la ciencia", el cual, por ende, no es un derecho autónomo, sino que forma parte de la libertad de investigación científica como una dimensión más, que no puede predicarse de personas concretas, sino de la sociedad o de la humanidad toda y que supone tanto el ejercicio de aquella como el despliegue de la actividad estatal para facilitar el acceso universal a sus resultados y beneficios.

Lo anterior concuerda con la consagración de este derecho en el artículo 15 del Pacto Internacional de Derechos Económicos, Sociales y Culturales, de 1966, y con el establecimiento de determinados deberes estatales relacionados con la investigación científica en los textos constitucionales, que en nuestra Carta Fundamental están contemplados, en términos generales, en el artículo $5^{\circ}$, inciso segundo, y en el artículo $19 \mathrm{~N}^{\circ} 10$, inciso sexto, que se refiere al deber de estimular la investigación científica y tecnológica.

\section{ALGUNAS NOCIONES GENERALES SOBRE LA INVESTIGACIÓN CIENTÍFICA, LA CIENCIA Y LA TECNOLOGÍA Y PARTICULARIDADES DE LA LIBERTAD DE INVESTIGACIÓN CIENTÍFICA}

La libertad de investigación científica, en términos generales, garantiza la realización sin trabas de todas las actividades destinadas a la búsqueda del conocimiento, en cualquier ámbito del saber, sea que se desarrolle de manera individual o colectiva, particularmente o dentro de instituciones públicas o privadas, sin perjuicio de respetar otros derechos, bienes jurídicos y valores constitucionalmente valiosos. Su objeto es el desarrollo de la ciencia a través de la investigación científica, nociones en las que me detendré como cuestión previa a la revisión de los diversos textos normativos, por su importancia para acotar el contenido de este derecho. Aludiré igualmente a los resultados derivados de su ejercicio, al principal producto de esa actividad, el conocimiento científico y también a los beneficios que de él derivan.

Alexy (2002) pp. 240-245 y especialmente, p. 241. Alexy utiliza precisamente el derecho que aquí analizamos como ejemplo para ilustrar el concepto de norma de derecho fundamental.

${ }^{19}$ Alexy (2002) p. 241.

${ }^{20}$ Chueca (2008) p. 11.

${ }^{21}$ Lo anterior no desconoce que en nuestro constitucionalismo los derechos fundamentales son concebidos principalmente como límites al poder, como libertades negativas, restando valor a las obligaciones positivas y prestaciones que los conforman. Véase, en este sentido, análisis crítico contenido en NASH (2005) pp. 119-146 y especialmente, pp. 127-128 y 134-135. 
La investigación puede ser definida como la actividad intelectual de búsqueda y ampliación del conocimiento. José María Martínez Val señala que la investigación es una actividad "intrínsecamente humana o, si se prefiere, diferencialmente humana" [...]; "investigar es seguir las huellas que encontramos en la apariencia de la naturaleza hasta conseguir entender, aunque sea despacio y con largo proceso de observaciones, medidas y pruebas, lo que hay dentro de la mera apariencia paladina o patente, que nos muestran las cosas"22.

La investigación científica se caracteriza por ser una actividad metódica que se presenta sistematizada, cualidad que la distingue de adquisición del conocimiento ordinario o vulgar, de carácter pragmático ${ }^{23}$.

La determinación de lo que es la ciencia, en cambio, es una tarea más compleja que difícilmente puede hacerse desde el Derecho. Según Javier García Fernández, la noción de ciencia que puede darse en este ámbito será "de carácter histórico, y no inmanente". Agrega el mismo autor, que si carecemos de una "aproximación jurídica" sobre lo que sea la ciencia "es porque, en definitiva, ni el poder constituyente ni el legislador ni la doctrina jurídica están capacitados para elaborar elementos definitorios sólidos de este concepto, pues es el operador no jurídico (el científico, el investigador, el técnico) quien tiene que aportar los materiales que se manejan en cada situación histórica”. Solo tras esta aportación, el jurista puede avanzar en una noción sin ninguna pretensión dogmática, sino simplemente orientativa ${ }^{24}$.

Por lo mismo optaré por mencionar solo los aspectos a que alude el término "ciencia”, que estimo suficientes para desarrollar, desde el punto de vista jurídico, el estudio del derecho que aquí me ocupa. Estos tres aspectos comprenden, en primer lugar, el resultado o producto final de la investigación científica, que en términos generales, corresponde al conocimiento científico. En segundo lugar, se refiere a la actividad humana, al trabajo de investigación que se lleva a cabo por los científicos ${ }^{25}$. Finalmente, designa al grupo de personas que se dedican a la investigación o comunidad científica ${ }^{26}$.

La relación que existe entre investigación científica y ciencia permite sostener a Rodríguez-Drincourt que “la investigación individualiza el 'momento dinámico' en el que

\footnotetext{
${ }^{22}$ Martínez VAL (1988) p. 2.497. Lo anterior nos configura, agrega, "como seres que buscan la realidad más profunda de las cosas", la esencia o la verdad.

${ }^{23}$ Dentro del conocimiento intelectual se distinguen el conocimiento vulgar y de carácter pragmático y el conocimiento especializado. El conocimiento ordinario es conocimiento no especializado, al que se llega por experiencia y sentido común. Bunge (1979) pp. 319, 320 y 324. BRUfAU (1987), por su parte, distingue dentro del conocimiento intelectual el conocimiento vulgar, que es de tipo empírico, pragmático y común a todos los seres humanos, del conocimiento técnico (la antigua tekhné). Por encima de ellos, señala, están el saber científico y el saber filosófico.

${ }^{24}$ García Fernández (1996) pp. 226-228. Esto también significa que "los poderes han de promover lo que la sociedad entiende por ciencia en cada momento histórico, sin entrar en debates metodológicos u ontológicos" (p. 227). Incluso en la literatura específica sobre la ciencia, se puede encontrar una postura similar. ChaLmers (2000) sostiene que "no existe una descripción general de la ciencia y del método científico que se aplique a todas las ciencias en todas las etapas históricas de su desarrollo" (p. 231). Para Bernal (1989) dar una definición de ciencia es una empresa fútil. "La ciencia es tan vieja, ha sufrido tantos cambios a lo largo de su historia, está tan encadenada en cada punto a las restantes actividades sociales que cualquier tentativa de definición -y han sido muchas- solo puede expresar más o menos inadecuadamente uno de los aspectos, tal vez de importancia secundaria, que ha tenido en algún período de su desarrollo", pp. 26-27.

${ }^{25}$ Bunge (1989) p. 19.

${ }^{26}$ Bunge (1988) p. 6.
} 
se adquieren nuevos conocimientos", diferente del "momento estático", de aquel en que "se plasman los resultados". Entrelazando ambas nociones el mismo autor concluye que "la ciencia expresa el patrimonio del conocimiento adquirido por la investigación" 27 .

En otras palabras, la ciencia como cuerpo de conocimiento es el resultado de la investigación científica. Esta actividad previa mediante la cual se aumenta el conocimiento, consistente en diversas actuaciones realizadas para descubrir algo, la realización sistemática de actividades intelectuales y, en algunos casos, de experimentación, con el propósito de aumentar o modificar los conocimientos sobre una determinada materia o asunto ${ }^{28}$.

Aunque habitualmente cuando se habla de ciencia, se suele restringir su concepto solo a las ciencias experimentales, como consecuencia de la distinta consideración social de las diferentes ramas científicas ${ }^{29}$, debemos entender que la libertad de investigación científica ampara la búsqueda del conocimiento en cualquier ámbito de la ciencia, entendida esta en un sentido amplio, comprendiendo tanto a aquellas como a las humanidades.

El Derecho y específicamente las normas que regulen el ejercicio de la libertad de investigación científica deben establecer la protección más amplia posible a la búsqueda del conocimiento, cualquiera sea la rama de la ciencia a que se refiera, esto es, que comprenda las ciencias del espíritu y las ciencias de la naturaleza, las humanidades y las ciencias experimentales. No existe razón jurídica alguna que justifique una protección restringida a las actividades desplegadas solo en algunas ramas científicas, pues la garantía que brindan los derechos humanos siempre debe interpretarse en un sentido extensivo.

La aseveración anterior también se fundamenta en un argumento histórico, pues en sus orígenes las ciencias no constituían reinos separados, estaban unidas por la "vocación científica", por el ansia de conocer ${ }^{30}$. Es la ciencia en sentido amplio la que ha planteado problemas. En el pasado, fue el pensador especulativo perteneciente a las humanidades el que entró en conflicto "con la ley y la moralidad de su tiempo" 31 . Hoy, en cambio, algunos de los problemas más urgentes, tanto para el Derecho como para la misma ciencia y en general para la sociedad, provienen principalmente de disciplinas empíricas, tanto de las ciencias sociales como de las naturales y dentro de estas hay ámbitos en los que ya existe una incipiente regulación.

Algunos autores postulan conceptos más amplios tanto de la ciencia como del conocimiento, relacionando ambas nociones con la creatividad humana en general, con la finalidad de proteger otras formas de conocimiento que no se obtienen a través de métodos científicos, como los conocimientos tradicionales de las comunidades indígenas y campesinas. En este sentido, Vandana Shiva, sostiene que "la ciencia es una empresa pluralista que remite a "formas de conocimiento diferentes" y agrega, que "no se puede utilizar el término

\footnotetext{
27 Rodríguez-Drincourt (2002) p. 137.

${ }^{28}$ Gómez (2007) p. 3.

${ }^{29}$ Torres del Moral (1984) p. 220. En sentido restringido se utiliza la expresión "ciencia” para aludir a alguna clase de ciencia en particular, es decir, a las ciencias físicas, las ciencias experimentales, las ciencias naturales, etc. NúÑEz de Castro (2000), especialmente pp. 153-155.

${ }^{30}$ GONZÁLEZ (1999) pp. 27-28.

${ }^{31}$ ESER (1987) p. 571.
} 
'ciencia' para referirse a la ciencia occidental moderna, pues debería incluir los sistemas de conocimiento de diversas culturas en distintos períodos de la historia" 32 .

El conocimiento es el principal resultado del ejercicio de la actividad científica. Pero también derivan de ella otros "productos indirectos", los beneficios. Estos se relacionan con el "derecho" de toda la colectividad a acceder y a disfrutar de los resultados de la ciencia, que, como se dejó enunciado, también forma parte del contenido del derecho en estudio.

El artículo $19 \mathrm{~N}^{\circ} 10$, inciso sexto, de nuestra Carta Fundamental, que consagra el derecho a la educación, es la única norma constitucional que alude tangencialmente a la investigación científica y tecnológica, solo en lo que respecta al deber del Estado de estimular dichas actividades. Esta circunstancia nos obliga a efectuar también algunas precisiones sobre la relación entre ciencia y tecnología, expresión esta última que en términos amplios, se corresponde con la aplicación del conocimiento científico.

Se puede decir que la ciencia y la tecnología son expresiones de la libertad creadora del ser humano, que se materializan en obras humanas, esto es, en conocimiento teórico y en artefactos o modelos de lo abstracto y lo concreto $^{33}$. Al decir de Edgard Roy Ramírez, mientras que el producto de la ciencia es el conocimiento, la tecnología se traduce "en un objeto, una situación tecnológica o una serie de procedimientos con vistas a la obtención de una función deseada ${ }^{34}$.

Lo anterior interesa también porque hoy en día las relaciones e interdependencia entre ciencia y tecnología son innegables. La convergencia entre ambas se da al menos en dos sentidos. Primero, existe una unión casi inmediata entre el conocimiento y las aplicaciones prácticas, de manera que hay continuidad entre ellas. En segundo lugar, la utilización de nuevas tecnologías facilita la investigación o la búsqueda del conocimiento. En este último sentido, la ciencia no consiste en pura teoría ni la tecnología en pura aplicación, de modo que los resultados de la actividad científica no podrían ser separados de los instrumentos que se utilizan en su elaboración. Esa interacción entre investigación y tecnología da lugar a lo que algunos autores consideran una nueva modalidad de ciencia, la denominada "tecnociencia" 35.

Hechas las precisiones anteriores, podemos terminar este apartado señalando algunas de las particularidades de la libertad de investigación científica, que la distinguen de los derechos con los que suele confundirse.

En primer lugar, sus titulares son distintos de los que ejercen la libertad de expresión y la libertad de cátedra, aunque a veces coincidan, como cuando se difunden o transmiten contenidos científicos mediante su publicación y la enseñanza, según el caso. La titularidad

\footnotetext{
32 Shiva (2003) p. 27. La misma idea se advierte en la Observación General $\mathrm{N}^{\circ} 17$, de 21 de noviembre de 2005, del Comité de Derechos Económicos, Sociales y Culturales -apartado II, párrafo 9- que entiende, en lo que aquí interesa, que en el artículo 15 letra c) del Pacto la "producción científica" se refiere a las creaciones de la mente humana únicamente, es decir, "las creaciones científicas", como publicaciones e innovaciones científicas, incluidos los conocimientos, innovaciones y prácticas de las comunidades indígenas o locales (p.6). E/C.12/GC/17. Disponible en http://portal.unesco.org/culture/es/files/30545/11432108781Comment_sp.pdf/ Comment_sp.pdf. [Consultada el 24 de marzo de 2011].

${ }^{33} \operatorname{Liz}(1995)$ pp. 31-33.

${ }^{34}$ RAMÍREZ (1987) p. 10.

35 González García; López Cerezo y Luján López (1996) p. 87. La interdependencia entre una y otra es tal "que no hay progreso científico sin avance tecnológico y viceversa", Echeverría (2001) pp. 221-222.
} 
de la libertad de investigación científica es universal. La afirmación anterior debe ser matizada, pues si bien es cierto que todos tienen la oportunidad de ejercer este derecho, sin restricciones de ninguna especie, no es menos efectivo que ese ejercicio se asocia a quienes cumplen una determinada función social, los científicos, es decir, quienes desarrollan la actividad científica de manera sistemática. Ello por cuanto, una cosa es el titular del derecho en abstracto -cualquier ser humano por el hecho de serlo-, y otra distinta es el titular real, el que efectivamente se dedica a la investigación, es decir, quien tiene la oportunidad, la capacidad y el interés de desarrollar esa actividad.

Considerando la estructura de la libertad de investigación científica en tres dimensiones -el ámbito de no injerencia, la faceta prestacional y la dimensión colectiva- puede sostenerse en cuanto a su naturaleza jurídica, que estamos ante un derecho de libertad con una dimensión prestacional, que conserva los rasgos de la libertad individual, que lo identifican, pero respecto del cual el Estado ha ido asumiendo paulatinamente obligaciones de promoción, con el fin de facilitar su ejercicio y lograr una más efectiva realización ${ }^{36}$.

Ello no significa que el ámbito de autonomía del titular -o de no interferencia- sea relegado a un segundo plano, pues ambos aspectos del derecho, el individual y el promocional, se complementan, dando lugar a un derecho complejo o mixto. Lo anterior en atención a que hoy en día los derechos de libertad "no siempre comportan exclusiva o esencialmente obligaciones generales de abstención”, de parte de los poderes públicos, puesto que estos también deben proteger y defender estos derechos, "lo que implica una serie de actividades positivas" 37 .

Finalmente, cabe señalar que la libertad de investigación científica, al igual que todos los derechos no tiene un carácter absoluto, sino que está sujeta a límites que afectan a su ejercicio $^{38}$. Este último asunto excede las pretensiones de este trabajo, razón por la que me limitaré a señalar que estos límites son diferentes a los de la libertad de expresión y que últimamente algunos autores vienen insistiendo en la necesidad de incluir en los textos constitucionales, entre otras, las cuestiones bioéticas para solucionar, por esta vía, los problemas más acuciantes en la actualidad, que derivan de la ciencia y de la tecnología aplicadas al ser humano, sin perjuicio de su regulación legislativa ${ }^{39}$.

\footnotetext{
36 En este aspecto, sigo principalmente la clasificación de los derechos según su contenido y forma de ejercicio, conforme a la cual se distingue entre derechos de libertad, no interferencia (o derechos de autonomía); derechos de prestación; derechos de participación y derechos deber. Pecees-Barba Martínez (1999) pp. 127-130; PrieTo SANChís (1989) pp. 127-130, Lo anterior, complementado con el planteamiento de Cossio sobre la presencia de las prestaciones en los derechos (1989) pp. 85 y ss. y 174 y ss.

${ }^{37}$ Palombella (2006) p. 53.

${ }^{38}$ Véase, en este sentido, la sistematización de los límites que hacen De Lora y Gascón (2008) especialmente, pp. 286 y ss. Estos autores distinguen entre límites externos (sobre qué se puede investigar) y límites internos (qué se puede o debe hacer cuando se investiga) o límites al ejercicio de la actividad científica, dentro de la cual quedan comprendidas la experimentación con humanos; la investigación con embriones humanos y la experimentación con animales no humanos.

${ }^{39}$ Gros Espiell (1998) p. 140; Bellver Capella (1999) pp. 67- 70; Cumplido (2005) p. 578.
} 


\section{EL RECONOCIMIENTO DE LA LIBERTAD DE INVESTIGACIÓN CIENTÍFICA EN LAS CONSTITUCIONES}

En este apartado revisaré algunos textos constitucionales, históricos y vigentes, con el fin de establecer, a grandes rasgos, la forma como se ha protegido constitucionalmente la libertad de investigación científica en los distintos ordenamientos jurídicos.

Haciendo un poco de historia sobre la positivación del derecho que nos ocupa, hay que decir que en épocas preconstitucionales, él no apareció expresamente consagrado en las primeras declaraciones de derechos. La razón de esta omisión probablemente se debió a que la investigación fue considerada una facultad más de los derechos consagrados expresamente, como las libertades de pensamiento y de expresión del mismo.

La consagración constitucional de la libertad de investigación científica se produce por primera vez en el ámbito germano, entre los años 1849 y 1919. La libertad de la ciencia aparece contemplada expresamente dentro de los derechos fundamentales, en el artículo 152 de la Constitución del pueblo alemán, aprobada en la Iglesia de San Pablo de Frankfurt, de 1849, disposición conforme a la cual "la ciencia y su doctrina son libres" ${ }^{0}$. Esta norma, sin embargo, solo debe considerarse como un mero antecedente del derecho en estudio, porque el aludido cuerpo normativo nunca entró en vigor ${ }^{41}$. La libertad de investigación científica, con la misma denominación antes aludida también se consagró en el artículo 20 de la Constitución prusiana de 1850, recogiéndose años más tarde y con una fórmula similar en el artículo 142 de la Constitución del Reich alemán, también conocida como Constitución de Weimar, de $1919^{42}$.

Esa formulación vaga y amplia del artículo 142 de la Constitución de Weimar y de su antecedente, se refiere al amparo de dos actividades creativas, esto es, la libertad de la ciencia y de las artes y será posteriormente recogida, en términos similares, por muchas constituciones ${ }^{43}$.

Esa fórmula con la que se reconoce explícitamente la libertad de investigación científica en las constituciones liberales, es el fiel reflejo de lo que Esteve Pardo denomina "el paradigma Galileo", que normativamente se traduce en una libertad absoluta, intangible e incondicionada, concepción que no se corresponde con las transformaciones que en los últimos años ha tenido la ciencia, ya sea en sus instituciones, organizaciones, métodos, etc. ${ }^{44}$.

\footnotetext{
${ }^{40}$ Mirkine-Guetzevich (1931) p. 87.

${ }^{41}$ Ello se debió a la resistencia de los príncipes regentes, que no aprobaron las "limitaciones a los privilegios monárquicos" implícitos en los principios y derechos recogidos en ella. SCHNEIDER (1979) p. 11; PolAKIEWICZ (1993) pp. 29 y 31. Su importancia, sin embargo, radica en que las ideas plasmadas en ella constituyeron un aporte determinante "para el desarrollo constitucional posterior" (p. 29).

42 De acuerdo al artículo 142, "El arte, la ciencia y su enseñanza, son libres. El Estado les garantiza la protección y vela por su cultivo".

${ }^{43}$ Así apareció consagrada en la Ley Fundamental del Estado sobre los derechos generales de los ciudadanos, de Austria, de 1867; en la Constitución del Estado Libre de Baviera, de 1919; en el Instrumento de Gobierno de Finlandia, de 1919; en la Constitución de Polonia, de 1921; en la Constitución del Reino de los Serbios, Croatas y Eslovenos, de 1921, en la Constitución de Grecia de 1927. Véase. Mirkine-Guetzevitch (1931); SeVilla (2004) p. 490.

${ }^{44}$ Esteve Pardo (2008) p. 1613. Los rasgos que identifican este paradigma son: 1) el desarrollo de la actividad científica en un entorno similar al de la actividad artística; 2) la absoluta autonomía y libertad del investigador
} 


\subsection{LA LIBERTAD DE INVESTIGACIÓN CIENTÍFICA EN LAS CONSTITUCIONES EUROPEAS}

Son varios los textos constitucionales europeos que se refieren expresamente al derecho en estudio. Revisaremos algunos de ellos a continuación.

En términos similares a los del artículo 142 de la Constitución de Weimar, del cual deriva directamente, el artículo 5.3 de la Constitución alemana, de 1949, se refiere a la actividad científica al tratar la libertad de expresión, utilizando la formulación amplia de aquella y conforme a la cual, "El arte y la ciencia, la investigación y la enseñanza son libres. La libertad de enseñanza no exime de la fidelidad a la Constitución”.

En esta disposición la investigación aparece vinculada claramente a la docencia y ello es reflejo del vínculo también existente entre libertad de cátedra y libertad de investigación científica ${ }^{45}$.

Tanto la doctrina como la jurisprudencia del Tribunal Constitucional Federal alemán han entendido que esa disposición garantiza el ejercicio de la libertad en sentido amplio, es decir, sin limitarlo a una determinada y específica clase de ciencia ${ }^{46}$. Ante las nuevas tecnologías y sus aplicaciones, el debate jurídico se ha centrado, hoy en día, en la protección de la dignidad humana (artículo 1.1 de la Constitución alemana) y del derecho de autodeterminación de los afectados frente al ejercicio de la libertad de investigación científica ${ }^{47}$.

La Constitución española, de 1978, se refiere a la libertad de investigación científica en dos disposiciones iusfundamentales, los artículos 20.1 letra b) y 44.2, que pese a encontrarse en enunciados constitucionales distintos, pueden ser considerados como partes integrantes de un único derecho fundamental. El primero, junto a la libertad de expresión, reconoce y ampara el derecho a "la producción y creación literaria, artística, científica y técnica"; mientras que el segundo -dentro de los principios rectores-, dispone que "los poderes públicos promoverán la ciencia y la investigación científica y técnica en beneficio del interés general” ${ }^{48}$.

La interpretación conjunta de esos dos enunciados constitucionales no representa la opinión unánime de los autores ${ }^{49}$, pero parece ser la más conveniente dado que concebidas de manera aislada originan múltiples interpretaciones. Ello no ocurre si, en cambio, se considera que esas dos disposiciones conforman un único derecho fundamental, que contempla una dimensión de autonomía, una dimensión colectiva y una faceta prestacional $^{50}$.

y 3) la separación entre conocimiento científico y aplicación técnica (pp. 1616-1617), que hoy se encuentra superado por un nuevo paradigma, el de la tecnociencia (p. 1619); JonAs (1997) pp. 57, 65.

45 VIDAL (2001) especialmente p. 29.

46 Knoepffler y Dettweiler (2002) citan una sentencia del Tribunal Constitucional Federal Alemán -BverfGE 35,79 (113)-, según la cual, actividad científica es definida como "aquello que, por su contenido y su forma, debe ser considerado como un intento serio y planificado de descubrimiento de la verdad". En este sentido, postulan que el art. 5.3 no protege una determinada concepción de ciencia o una determinada teoría científica y que este derecho comprende todas las actividades de investigación junto con las necesarias medidas preparativas y de estímulo. p. 58.

47 BeNdA (2001) p. 134.

48 En la Constitución española hay otras dos disposiciones que se refieren a la actividad científica, los artículos 148.1.17 y 149.1.15, ambos sobre aspectos competenciales.

49 Puede apreciarse, por ejemplo, en Pelayo (2002) p. 241; Peces-Barba (1994) p. 330; Romeo Casabona (1996) p. 133.

${ }^{50}$ Este es uno de los planteamientos que la autora desarrolló en su tesis de grado, La libertad de investigación cientifica. Fundamentos filosóficos y consagración constitucional, inédita. 
Mayoritariamente, se entiende que el artículo 20.1 letra b) contempla la libertad de investigación científica. Pero, también ha sido interpretado por una minoría en un sentido muy restringido, entendiendo que solo se refiere a los derechos de autor ${ }^{51}$, aunque estos, con mayor propiedad, son "derechos posteriores a la producción o creación intelectual" 52 . Para otros autores, esa disposición es simplemente una modalidad de la libertad de expresión, por tanto, una reiteración o concreción de la misma ${ }^{53}$.

Cuestión similar ocurre con el artículo 44.2, al que generalmente se le reconoce un papel instrumental respecto de otros derechos, como el derecho de acceso a la cultura ${ }^{54} \mathrm{o}$ de la libertad de cátedra ${ }^{55}$.

En el plano legal, la ley $\mathrm{N}^{\circ}$ 14/2007, de 3 de julio, de Investigación Biomédica, garantiza la libertad de investigación científica y de producción científica -artículo 2 letra d)-, estableciendo el marco legal de ejercicio de este derecho en el ámbito de la biomedicina.

La Constitución italiana, de 1947, no se refiere a este derecho al tratar la libertad de expresión, sino que en dos disposiciones diferentes. El artículo 9.1, comprendido dentro de los "Principios Fundamentales", alude a los deberes del Estado, señalando que "la República promoverá el desarrollo de la cultura y la investigación científica y técnica”.

Más adelante, el artículo 33.1, ubicado en el título II de la Parte Primera, relativo a las "relaciones ético-sociales", siguiendo la fórmula que se había consagrado en la Constitución de Weimar, dispone que "El arte y la ciencia son libres, así como también su enseñanza”, refiriéndose posteriormente a los distintos órdenes y grados de instrucción.

Como se puede apreciar, aunque su consagración es independiente de la libertad de expresión, no es una libertad autónoma. Comentando el referido artículo 33.1, Alessandro Pizzorusso señala que las libertades artística y científica son especificaciones de la libertad de manifestación del pensamiento, a las cuales la Constitución dedica una atención especial, que adoptan "un significado peculiar por el hecho de desenvolverse en el ámbito de ese complejo de actividades que integran la 'cultura y la investigación científica y técnica', y al que se refiere el art. $9^{0}{ }^{\circ 6}$. De esta manera, pareciera entender también que ambas disposiciones deben interpretarse armónicamente, relacionando la dimensión de autonomía de la libertad con la faceta prestacional.

La Constitución de Grecia, de 1975, con una redacción muy similar a la del texto constitucional de 1927, dispone en el artículo 16.1 que "son libres el arte y la ciencia, la investigación y la enseñanza, y su desarrollo y promoción constituyen una obligación del Estado" 57 , haciendo una referencia a la dimensión de autonomía y al deber de promoción del Estado.

\footnotetext{
${ }^{51}$ Fernández-Miranda Campoamor y García Sanz (1997) pp. 520-547; Plaza Penadés (1997) especialmente pp. 183 y ss.

52 Fernández Segado (1992) p. 334; Gómez Diez (1995) p. 190.

53 De Carreras (1991) p. 11; Barceló I Serramalera (2004) pp. 569 y 581.

${ }^{54}$ Ruiz-Rico y Pérez Sola (2002) pp. 1613-1614 y 1616-1617.

55 Cueto (2002) pp. 96, 98 y 100.

56 Pizzorusso (1981) p. 128. La especial referencia que hace la Constitución no tiene como fin atribuirle una tutela más acentuada, sino que se debe a que plantean problemas específicos o para poner énfasis en su importancia.

${ }^{57}$ Art. 21 de la Constitución Helénica de 1927. Vid. Mirkine- Guetzevitch (1931) p. 296.
} 
La Constitución de Portugal, de 1976, consagra la libertad de investigación científica en una disposición distinta de la que reconoce la libertad de expresión, aunque tampoco la considera un derecho autónomo. En efecto, la comprende dentro de una genérica "libertad de creación cultural” a la que se refiere el artículo 42 en los siguientes términos: "1. La creación intelectual, artística y científica es libre. 2. Esta libertad comprende el derecho de invención, producción y divulgación de la obra científica, literaria o artística incluida la protección legal de los derechos de autor".

La primera parte de esta disposición tiene una formulación similar a la de los textos constitucionales anteriormente citados, agregando una referencia a otros aspectos de la actividad científica, como la "invención”, la "producción” y la "divulgación”, contemplando especialmente los derechos de autor, que son derechos posteriores a la creación intelectual ${ }^{58}$.

La Constitución portuguesa se refiere a los deberes constitucionales del Estado respecto de la actividad científica en el artículo 77, según el cual: “1.- La creación y la investigación científicas serán estimuladas y protegidas por el Estado. 2.- La política científica y tecnológica tendrá por finalidad el fomento de la investigación fundamental y de la investigación aplicada, con preferencia por los campos que interesan al desarrollo del país, considerando la progresiva liberación de dependencias externas en el ámbito de la cooperación y del intercambio con todos los pueblos".

Esta disposición incorpora al ámbito constitucional la distinción entre investigación básica e investigación aplicada, aunque, sin mayores consecuencias jurídicas, pues se dice que ambas deben ser fomentadas, estableciendo que la preferencia estará determinada por las líneas de investigación de interés nacional ${ }^{59}$.

Finalmente, el texto luso dispone en el artículo 26.3 que "la ley garantizará la dignidad personal y la identidad genética del ser humano, especialmente en la creación, desarrollo y utilización de la tecnología y en la experimentación científica”. Alude así, de manera amplia, al establecimiento de límites a la aplicación de conocimientos científicos y a la actividad investigativa de experimentación, aspectos en los cuales el legislador ha de considerar los derechos humanos que eventualmente pueden verse afectados y la dignidad humana que les sirve de fundamento.

La Constitución Federal de la Confederación Suiza ${ }^{60}$ se refiere a la "libertad científica" en el artículo 20, en términos bastante escuetos, señalando que "se garantiza la libertad de enseñanza e investigación científica”, vinculando la actividad investigativa con la libertad que ampara la transmisión de los conocimientos.

Esa disposición tiene que concordarse con el artículo 64 del mismo texto constitucional, que consagra los deberes de fomento y promoción de la actividad científica por parte del Estado y conforme al cual: 1. La Confederación fomentará la investigación científica. 2. Podrá hacer depender su promoción especialmente de la puesta en práctica de medidas

${ }^{58}$ Véase, Cueto (2002) pp. 96, 98 y 100.

${ }^{59}$ Este aspecto aparece desarrollado con mayor claridad, como se verá, en la Constitución de Brasil, que incorpora la misma referencia aunque en lugar de ciencia fundamental utiliza la expresión sinónima de investigación científica básica.

${ }^{60} \mathrm{La}$ amplia reforma del año 1999 incluyó una nueva y extensa formulación de los derechos fundamentales en este texto constitucional. 
de coordinación. 3. La Confederación podrá gestionar, crear o hacerse cargo de centros de investigación.

El breve enunciado del artículo 20 de la Constitución suiza, que consagra la libertad de investigación científica, contrasta con la minuciosa regulación del artículo 119, que se refiere a la procreación asistida y a otras materias relacionadas con la aplicación de las nuevas tecnologías a los seres humanos. Siguiendo la actual tendencia, establece algunos límites a la actividad médica y a la investigación científica en el ámbito de la ingeniería genética y de la reproducción humana. Conforme a la aludida disposición: "1. El ser humano deberá ser protegido contra los abusos en materia de procreación asistida y de ingeniería genética. 2. La Confederación legislará sobre la utilización del patrimonio germinal y genético humano. Al hacerlo tiene por objeto asegurar la protección de la dignidad humana, de la personalidad, de la familia y deberá respetar, fundamentalmente, los siguientes principios: a) toda forma de clonación y toda intervención en el patrimonio genético de gametos y embriones humanos están prohibidas; b) el patrimonio genético y germinal no humano no puede ser transferido al patrimonio germinal humano ni fusionado con el mismo; c) el recurso a los métodos de procreación asistida no será autorizado más que cuando la esterilidad, o el peligro de transmisión de una grave enfermedad, no puedan ser descartados de otro modo y nunca para desarrollar en el niño ciertas cualidades o para investigar; la fecundación de óvulos humanos fuera del cuerpo de la mujer no será autorizada sino con las condiciones previstas en la ley; no podrán ser desarrollados hasta el estado de embrión más que el número de óvulos humanos que puedan ser, inmediatamente, implantados; d) la donación de embriones y cualquier tipo de maternidad sustitutiva están prohibidos; e) no puede comerciarse con material germinal humano ni con los productos resultantes de los embriones; f) el patrimonio genético de una persona no puede ser analizado, registrado y dado a conocer más que con el consentimiento de esta o en virtud de una ley; g) toda persona tendrá acceso a los datos relativos a su ascendencia" ${ }^{61}$.

Esta disposición exhaustiva a base de principios redactados de manera muy amplia, fija el marco al que deberá ajustarse la legislación complementaria ${ }^{62}$.

Disposiciones como la que se ha reproducido, nos llevan a concluir que al establecer el marco legítimo de actuación del derecho que nos ocupa se deben considerar tanto las amplias posibilidades de la ciencia como los riesgos que representa el ejercicio de la libertad que la ampara, considerando especialmente su relación con otros derechos fundamentales y bienes jurídicamente protegidos. El Estado debe velar porque la regulación no se transforme en frenos a la creatividad, a la natural curiosidad e ingenio del ser humano,

\footnotetext{
${ }^{61}$ Se transcriben este y el anterior artículo omitiendo los puntos apartes y separaciones consiguientes después de cada número y letra. Sánchez Ferriz y García Soriano (2002) pp. 174 y ss. (El texto constitucional completo está contenido en un Anexo, pp. 157 y ss.). Además de las disposiciones transcritas, el artículo 120 de la referida Constitución contempla el deber de protección al ser humano y a su entorno de eventuales abusos derivados de la ingeniería genética aplicada en el ámbito no humano.

${ }^{62}$ Las autoras citadas en la nota anterior, en cambio, opinan que en general las disposiciones sobre derechos humanos de la Constitución suiza son "ejemplos de buena técnica jurídica", destacando "la forma clara y concisa sin mención de límites concretos" y especialmente, que "la declaración de derechos no queda "sobredimensionada por la previsión de las nuevas exigencias derivadas de las investigaciones genéticas”. SánCHEZ FÉRrIZ y García Soriano (2002) pp. 57-58.
} 
proporcionando los medios para promover e incentivar el progreso científico y la innovación tecnológica, velando, al mismo tiempo porque los intereses económicos de consorcios privados, nacionales e internacionales, que desarrollan actividades científicas -en definitiva, el mercado y sus propios intereses-, no desvirtúen la libertad de investigación científica ni vulneren otros derechos.

\subsection{LA LIBERTAD DE INVESTIGACiÓN CiENTÍfica EN LAS CONSTITUCiONES AMERICANAS}

Dentro de los documentos de la historia constitucional norteamericana, en el período previo a la Declaración de Independencia, cabe destacar el llamamiento dirigido a por el Primer Congreso Continental a los habitantes de Quebec, para que adhirieran a la causa de las colonias, de 26 de octubre de 1774. En este instrumento se enumeran, entre otros derechos, la libertad de expresión, destacando sus virtudes al manifestar su importancia para "el avance de la verdad, la ciencia, la moralidad y las artes en general”. Se le reconoce así como instrumento de difusión del conocimiento y como medio para el progreso del saber ${ }^{63}$. Tal es su importancia de este documento que ha sido citado en algunos fallos, confirmados por la Corte Suprema, como evidencia del pensamiento de los primeros colonos y para incluir el discurso científico dentro de la protección de la primera enmienda ${ }^{64}$.

La Constitución de Estados Unidos, de 1787, que sigue a la Declaración de Independencia, careció inicialmente de un catálogo de derechos. Para salvar esta omisión, el 15 de diciembre de 1791 se adoptaron y ratificaron las diez primeras enmiendas a la Constitución. La primera enmienda consagra la libertad de expresión, señalando en lo que aquí interesa que "El Congreso no hará ley alguna por la que se establezca una religión, o se prohíba ejercerla, o se limite la libertad de palabra o la de la prensa...”.

En la parte reproducida, el texto refleja una concepción amplia de la libertad de expresión $^{65}$, la misma que, más adelante, permitirá entender tácitamente comprendida en ella a la libertad de investigación científica y amparar el discurso científico ${ }^{66}$.

El modelo americano, entonces, se caracteriza porque no consagra de manera expresa la libertad de investigación científica, lo que no significa que esté desprotegida. Esta conclusión es extrapolable a todos aquellos ordenamientos jurídicos que no contemplan dicho derecho, o que solo regulan algunos de sus aspectos, como los deberes del Estado.

La Constitución Politica de los Estados Unidos Mexicanos, de 1917, se refiere en el artículo 3.V solamente al deber del Estado de apoyar la investigación científica y tecnológica. Esta parte de la norma constitucional es complementada por la llamada Ley de la Ciencia, que en el artículo 12 sí consagra la libertad de investigación científica.

Dentro de los textos constitucionales que integran el ámbito constitucional iberoamericano, hay algunos cuya regulación destaca, como las Constituciones de Brasil y Colombia, que parecen ser las más completas en el aspecto que aquí se analiza y a cuyas

\footnotetext{
63 EMERSON (1976-1977) p. 743.

${ }^{64}$ Delgado y Millen (1977-1978) p. 356.

65 Ansuátegui (1994) p. 379.

${ }^{6}$ Stetten (1975) pp. 416 y 425; Emerson (1976-1977) pp. 737-760; Ferguson (1978-1979) pp. 639-665.
} 
disposiciones me referiré en lo que sigue. Esta selección obedece únicamente al tratamiento especial que se da a la ciencia en estos textos y a su mayor desarrollo ${ }^{67}$.

La Constitución de la República Federativa de Brasil, de 1988, se caracteriza por su extensión y no hace una excepción al referirse a la ciencia. Regula detalladamente sus diversos aspectos, ya sea como actividad; en cuanto resultado, considerando el conocimiento como un bien que forma parte del patrimonio cultural y como contenido divulgado y protegido a través del ejercicio de la libertad de expresión. Le dedica un capítulo especial denominado "de la ciencia y tecnología" y la menciona al establecer algunos de los deberes del Estado. Sin embargo, aunque alude de manera expresa a la libertad de investigar, la entiende como un principio inspirador de la enseñanza y no como un derecho fundamental específico que ampare la actividad científica.

Entre las constituciones iberoamericanas es la que el artículo 5.IX dispone que "es libre la expresión de la actividad intelectual, artística, cientifica y de comunicación, sin necesidad de censura o licencia", haciendo una referencia expresa a la libre difusión de los contenidos científicos.

El artículo 206.II contempla, dentro de los principios conforme a los cuales se imparte la enseñanza, la "libertad de aprender, enseñar, investigar y divulgar el pensamiento, el arte y el saber". Más adelante, el artículo 214 .V se refiere a los fines del plan nacional de educación, que debe establecerse por ley, mencionando entre aquellos a la promoción humanística, cientifica y tecnológica del país. En el artículo 216.III considera las creaciones científicas dentro de los bienes que se incorporan al patrimonio cultural brasileño.

La faceta prestacional del derecho es regulada por los artículos 218 y 225. El primero de ellos, de manera similar a la Constitución de Portugal ${ }^{68}$, se refiere al deber del Estado de promover e incentivar "el desarrollo cientifico, la investigación y la capacitación tecnológica"; al tratamiento prioritario de la investigación científica básica; al apoyo e incentivo de la inversión privada en ciencia y tecnología, y a la formación y perfeccionamiento de las personas dedicadas a estas actividades. La misma disposición establece, en el $N^{\circ} 1$, que la investigación científica básica recibirá tratamiento prioritario del Estado, teniendo en cuenta el bien público y el progreso de la ciencia. Agrega, en el $\mathrm{N}^{\circ} 2$, que la investigación tecnológica se dirigirá prioritariamente a la solución de los problemas brasileños y al desarrollo del sistema productivo regional. De esta manera, distingue entre la investigación científica básica y la investigación tecnológica para el efecto de señalar el tratamiento prioritario que debe darse a la primera y los fines que debe perseguir la segunda.

Finalmente, el artículo 225.II, en el capítulo destinado al medio ambiente, contempla dentro de los deberes que se imponen a los poderes públicos para garantizar este

\footnotetext{
${ }^{67}$ Hay otras Constituciones latinoamericanas, a las que no me referiré in extenso, que regulan también la actividad científica, como la Constitución Política de la República de Costa Rica (artículo 89); la Constitución de la República de Cuba (artículo 39 inciso $1^{\circ}$ ); la Constitución Política de la República de Guatemala (artículos 59, 63 y 80); la Constitución de la República de Honduras (artículo 155); la Constitución de la República de Perú (artículos $2 \mathrm{~N}^{\circ}$ 8; 14; 18 inciso $1^{\circ}$ ); la Constitución de la República Oriental de Uruguay (artículo 70, inciso $2^{\circ}$ ); la Constitución de la República de Panamá (artículos 76, 77 y 79).

${ }^{68}$ Véase artículo 77 de la Constitución de Portugal de 1976, citado en el acápite anterior.
} 
derecho, el de "fiscalizar a las entidades dedicadas a la investigación y manipulación del material genético".

La Constitución Politica de Colombia, de 1991, se refiere a la ciencia y a la investigación científica en diversas disposiciones, contenidas principalmente en el capítulo relativo a los derechos económicos, sociales y culturales. Consagra la libertad de investigación científica en el artículo 71, según el cual "la búsqueda del conocimiento y la expresión artísticas son libres. Los planes de desarrollo económico y social incluirán el fomento a las ciencias y, en general, a la cultura. El Estado creará incentivos para personas e instituciones que desarrollen y fomenten la ciencia y la tecnología y las demás manifestaciones culturales y ofrecerá estímulos especiales a personas e instituciones que ejerzan estas actividades".

El artículo 70, inciso final, contempla los deberes del Estado, disponiendo en términos generales que "el Estado promoverá la investigación, la ciencia, el desarrollo y la difusión de los valores culturales de la Nación", deberes que en el ámbito universitario, según el artículo 69, inciso tercero, se traducen en que aquel "fortalecerá la investigación científica en las universidades oficiales y privadas y ofrecerá las condiciones especiales para su desarrollo”.

También se refiere a la ciencia el artículo 67 que, al tratar el derecho a la educación, menciona dentro de los fines que persigue la educación, "el acceso al conocimiento, a la ciencia, a la técnica" y otros "valores de la cultura".

Finalmente, el artículo 81, dentro del capítulo destinado a los derechos colectivos y del ambiente, contempla algunos límites al disponer que "queda prohibida la fabricación, importación, posesión y uso de armas químicas, biológicas y nucleares, así como la introducción al territorio nacional de residuos nucleares y desechos tóxicos", agregando en el inciso segundo, que "el Estado regulará el ingreso al país y la salida de él de los recursos genéticos y su utilización, de acuerdo con el interés nacional”.

En síntesis, del análisis de los textos constitucionales precedentemente citados se desprende que existen básicamente dos modelos de regulación expresa de la libertad de investigación científica, esto es, aquel que la consagra de manera autónoma y el que la considera junto con otros derechos con los que está estrechamente relacionada, esto es, junto a la libertad de expresión o a la libertad de enseñanza. En ellos se recurre generalmente a la fórmula amplia que hace referencia conjuntamente a la libertad de las ciencias y de las artes.

En aquellos ordenamientos en los que no se consagra expresamente, la libertad de investigación científica se entiende tácitamente amparada por la libertad de expresión. En este último caso se encuentra nuestra Constitución, según hemos adelantado y veremos con más detalle.

Por otro lado, puede apreciarse como gran parte de los textos constitucionales contienen, disposiciones que se refieren a los deberes del Estado respecto de la actividad científica, que se consagran conforme aumenta la intervención de los Estados en el desarrollo de la ciencia.

Finalmente, se advierte que la tendencia actual es incorporar también en los textos constitucionales normas que regulen algunos aspectos de la investigación científica con el fin de proteger otros derechos y bienes jurídicos que eventualmente podrían resultar afectados por aquella, lo que se traduce en el establecimiento de límites a la libertad que la ampara. 


\section{LA LIBERTAD DE INVESTIGACIÓN CIENTÍFICA EN EL DERECHO INTERNACIONAL}

La libertad de investigación científica ha sido igualmente reconocida en diversos instrumentos internacionales que integran el derecho internacional de los derechos humanos. Un breve análisis de ellos nos permitirá desprender, a grandes rasgos, la evolución que ha experimentado en este ámbito. Ello también interesa porque conforme a lo dispuesto por el artículo $5^{\circ}$, inciso $2^{\circ}$, de la Carta Fundamental es deber del Estado respetar y promover los derechos esenciales que emanan de la naturaleza humana, garantizados por la Constitución y por los tratados internacionales ratificados por Chile y que se encuentran vigentes.

El interés de la comunidad internacional en la protección de la libertad de investigación científica se debe no solo a la necesidad de amparar el libre desarrollo de esta actividad intelectual; sino también a la conveniencia de proteger el resultado primario de su ejercicio, esto es, el conocimiento ${ }^{69}$, considerado un "bien común de la humanidad"70 y de garantizar, igualmente, el acceso equitativo a los beneficios que de él derivan.

En lo que sigue se revisaran los principales textos internacionales que consagran la libertad de investigación científica, de alcance universal y regional; también se verán algunos documentos no vinculantes auspiciadas por la UNESCO y, para finalizar, las declaraciones más recientes, también emanadas de ese mismo organismo, que establecen límites al ejercicio de esta libertad en ámbitos específicos de las ciencias de la vida, que son en los que se ha centrado el debate los últimos años, originando una incipiente regulación.

La Declaración Universal de Derechos Humanos, de 10 de diciembre de 1948, consagra la libertad expresión en el artículo 19, señalando que "todo individuo tiene derecho a la libertad de opinión y de expresión; este derecho incluye el de no ser molestado a causa de sus opiniones, el de investigar y recibir informaciones y opiniones, y el de difundirlas, sin limitación de fronteras, por cualquier medio de expresión".

El artículo 27.1 del mismo instrumento contiene una referencia específica a la ciencia y la cultura, al disponer que "toda persona tiene derecho a tomar parte libremente en la vida cultural de la comunidad, a gozar de las artes y a participar en el progreso científico y en los beneficios que de él resulten". Agrega, el mismo artículo, en el numeral dos, que "toda persona tiene derecho a la protección de los intereses morales y materiales que le correspondan por razón de las producciones científicas, literarias o artísticas de que sea autora”.

Adalsteinsson y Thorhallson sostienen que aunque usualmente se dice que esta disposición consagra los denominados derechos culturales, de hecho contiene varios derechos diferentes, que no pertenecen necesariamente a la misma categoría, dentro de los cuales es

\footnotetext{
${ }^{69}$ La libertad de investigación científica es considerada un elemento esencial en la sociedad del conocimiento. Véase, en este sentido, el numeral 6 de la Declaración de Santo Domingo: Gobernabilidad y Desarrollo en la Sociedad del Conocimiento, aprobada en la cuarta sesión plenaria, celebrada por la Organización de Estados Americanos, OEA, el 6 de junio de 2006.

${ }^{70} \mathrm{El}$ conocimiento científico tiene las propiedades necesarias para ser considerado como un bien público, lo que justificaría su extracción del mercado y su no privatización. Al igual que los bienes públicos, se caracteriza por la no rivalidad y la no exclusividad, es decir, porque cualquier persona puede hacer uso del conocimiento, sin que ello afecte a los demás y porque los beneficios que de él derivan están disponibles para todos. VeGA ENCABo (2001) pp.250-251; Broncano (2001) pp. 22-28.
} 
posible distinguir la libertad de creación artística; el derecho a disfrutar de la cultura; la libertad de investigación científica y, finalmente, los derechos de autor ${ }^{71}$.

El derecho a participar en el progreso científico y a gozar de sus beneficios a que se refiere esta última disposición se corresponde con la dimensión colectiva de la libertad de investigación científica. En virtud de ella, la comunidad y en general toda la humanidad debería poder disfrutar de los resultados de la investigación científica, del conocimiento y de las aplicaciones científicas y tecnológicas. Este denominado "derecho" no tiene, en mi opinión, carácter autónomo y de la misma manera que la libertad, del cual no es sino la otra cara de la misma moneda, debe entenderse en un sentido amplio, esto es, referido no solo al progreso experimentado por las ciencias biológicas, sino también por las ciencias sociales y las humanidades ${ }^{72}$.

Con posterioridad a la aprobación de la Declaración Universal de Derechos $\mathrm{Hu}$ manos, y dado que este documento carece de fuerza vinculante para los Estados, se inició un proceso de creación de normas que fueron estableciendo obligaciones específicas para aquellos, ideando un sistema de protección de derechos que garantizara su observancia y cumplimiento. Finalmente, se optó por dar un tratamiento separado a los derechos, con dos sistemas de protección, lo que se tradujo en dos tratados internacionales multilaterales, adoptados por la Asamblea General de las Naciones Unidas y conocidos como "Pactos de 1966", esto es, el Pacto Internacional de Derechos Civiles y Políticos y el Pacto Internacional de Derechos Económicos, Sociales y Culturales ${ }^{73}$.

El Pacto Internacional de Derechos Civiles y Politicos consagra, en el artículo 19.2, la libertad de expresión, señalando que esta comprende "la libertad de buscar, recibir y difundir informaciones e ideas de toda índole...", aludiendo en términos muy generales a la facultad de investigar.

El artículo 7 de este mismo instrumento prescribe que "nadie será sometido a torturas ni a penas o tratos crueles inhumanos o degradantes, agregando una especial referencia a uno de los límites que afectan a la investigación científica, al disponer que "nadie será sometido, sin su libre consentimiento, a experimentos médicos o científicos”.

Por su parte, el artículo 15 del Pacto Internacional de Derechos Económicos, Sociales y Culturales, después de consagrar el derecho a participar en la vida cultural (15.1.a), se refiere al derecho de toda persona a "gozar de los beneficios del progreso científico y de sus aplicaciones" (15.1.b) y a "beneficiarse de la protección de los intereses morales y materiales que le correspondan por razón de las producciones científicas, literarias y artísticas de que sea autora" (15.1.c). La misma disposición establece, entre las medidas que los Estados Partes deberán adoptar para asegurar el pleno ejercicio de este derecho, "las necesarias para la conservación, el desarrollo y la difusión de la ciencia y de la cultura” (15.2), comprometiéndose a "respetar la indispensable libertad para la investigación cientifica y para la actividad

\footnotetext{
71 Adalsteinsson y Thorhallson (1999) p. 575.

72 Eide (1995) p. 235.

73 El Pacto Internacional de Derechos Civiles y Políticos entró en vigor el 23 de marzo de 1976 y el Pacto Internacional de Derechos Económicos, Sociales y Culturales, el 3 de enero de 1976, conforme a las disposiciones contenidas en ellos mismos, esto es, los artículos 49 y 27 , respectivamente.
} 
creadora" (15.3) y a reconocer "los beneficios que derivan del fomento y desarrollo de la cooperación y de las relaciones internacionales en cuestiones científicas y culturales" (15.4).

La real trascendencia de esta disposición radica en que desarrolla derechos ya contenidos en declaraciones anteriores -verbigracia el artículo 27 de la Declaración Universal de Derechos del Hombre- y "les da, por primera vez, fuerza jurídica obligatoria en el plano internacional" 74 .

Este extenso artículo ha servido de base para sostener, como lo hace Luis Jimena Quesada, que evidencia la interdependencia existente entre los derechos y reafirma la naturaleza de "derechos mixtos", que tienen algunos de ellos, "en el sentido de que contienen facetas de las diversas categorías o generaciones". El mismo autor señala que el artículo 15 comprende primero, "un contenido espiritual o estrictamente cultural" (15.1.a); segundo, un "componente económico", al que se alude como los intereses materiales derivados de la producción científica, artística o literaria (15.1.c); tercero, "el derecho a gozar de los beneficios de la ciencia", que supone que todos podemos disfrutar por igual de ellos y que los Estados deben garantizar ese acceso (15.2); para finalmente comprender también "la vertiente de derecho cívico-político", la libertad negativa, es decir, la "indispensable libertad para la investigación científica y para la actividad creadora” (15.3) 75 .

Aunque la idea es similar, prefiero hablar de un derecho complejo, en el sentido que indudablemente estamos ante un derecho predominantemente de libertad que, como se ha dicho, comprende tres dimensiones o facetas que integran un solo todo: la dimensión negativa, de autonomía o individual; la dimensión colectiva, denominada también "derecho a gozar de los beneficios de la ciencia” y la dimensión prestacional, que comprende los deberes del Estado imprescindibles para su efectiva realización.

La disposición anotada distingue, además, entre la libertad que ampara el ejercicio de la actividad científica y los derechos que como autor tiene el titular sobre el resultado de ella o sobre lo creado, es decir, los beneficios particulares y económicos del producto resultante, como la propiedad intelectual y las patentes.

Por otro lado, los distintos convenios internacionales -europeo, americano y africano- correspondientes a los sistemas regionales de protección de los derechos humanos, que se enmarcan dentro del sistema de las Naciones Unidas, no aluden expresamente a la libertad de investigación científica.

En el ámbito europeo, no lo hace el Convenio para la protección de los derechos humanos -Convenio Europeo de Derechos Humanos o Convenio de Roma-, de 4 de noviembre de 1950, ni la Carta Social Europea de 1961, que lo complementa ${ }^{76}$.

\footnotetext{
${ }^{74}$ MaYorga (1996) p. 59

75 Jimena Quesada (1995) p. 69. No obstante el acertado análisis del artículo 15, el autor no es tan claro cuando sostiene que el derecho en estudio suele denominarse "libertad de la ciencia" o "libertad de cátedra", agregando que corresponde a una "manifestación de la libertad de expresión o también de la libertad de enseñanza", confundiendo ambas libertades.

${ }^{76}$ Jimena Quesada (1995) p. 73. Existió un intento de salvar esta omisión, pues el Consejo de Europa a través de un grupo de especialistas preparó un proyecto de Protocolo al Convenio, relativo al reconocimiento de derechos culturales, en el $8^{\circ}$ Coloquio de Friburgo, de 1991, celebrado entre el 28 y el 30 de noviembre en Suiza, que dio origen al documento denominado "Derechos culturales: una categoría subdesarrollada de derechos humanos”. Una versión final del proyecto de Declaración fue publicado en 1998 por la UNESCO. Estudios pos-
} 
En este mismo ámbito, la Carta de Derechos Fundamentales de la Unión Europea, proclamada en el Consejo Europeo de Niza, de 2000 y adoptada el 12 de diciembre de 2007 en Estrasburgo ${ }^{77}$, dispone en el artículo 13 que "las artes y la investigación científica son libres. Se respeta la libertad de cátedra”. Consagra la libertad de investigación científica autónomamente, sin relación con la libertad de expresión, aludiendo a la relación entre la investigación y la transmisión de lo investigado ${ }^{78}$.

El reconocimiento conjunto de la libertad de investigación científica y de la libertad de cátedra también aparece en otros instrumentos normativos y se debe, probablemente, a que ambos derechos nacen de las luchas del individuo frente a las autoridades políticas y religiosas que muchas veces intentaron controlarlo, interviniendo en los contenidos transmitidos a través de la enseñanza o haciendo manifiesta la disconformidad con algunos resultados de las investigaciones, determinadas teorías científicas o algunos descubrimientos científicos.

En un sentido similar al de los instrumentos aludidos y también en el ámbito europeo, el Convenio para la protección de los derechos humanos y la dignidad del ser humano con respecto a las aplicaciones de la Biología y la Medicina, llamado también Convenio de Oviedo, de 1999, impulsado por el Consejo de Europa, dispone en el artículo 15.1 que "la investigación científica en el ámbito de la biología y la medicina se efectuará libremente...”.

Tampoco la Convención Americana sobre Derechos Humanos, de 7 de abril de 1970, menciona la libertad de investigación científica. Para superar esa omisión, el Sistema Interamericano adoptó el Protocolo Adicional a la Convención Americana sobre Derechos Humanos en materia de Derechos Económicos, Sociales y Culturales, de 1988, conocido también como Protocolo de San Salvador, cuyo artículo 14 reconoce el derecho de toda persona a gozar de los beneficios del progreso científico y de sus aplicaciones ( $\mathrm{N}^{\circ} 1$, letra b). El $\mathrm{N}^{\circ} 2$ señala "entre las medidas que los Estados Partes en el presente Protocolo deberán adoptar para asegurar el pleno ejercicio de este derecho, figurarán las necesarias para la conservación, el desarrollo y la difusión de la ciencia, la cultura y el arte". El numeral 3 establece que los Estados Partes "se comprometen a respetar la indispensable libertad para la investigación cientifica y para la actividad creadora". Finalmente, de acuerdo con el numeral 4, los Estados Partes "reconocen los beneficios que se derivan del fomento y desarrollo de la cooperación y de las relaciones internacionales en cuestiones científicas, artísticas y culturales, y en este sentido se comprometen a propiciar una mayor cooperación internacional sobre la materia”.

En este ámbito merece una especial mención la Declaración Americana de los Derechos y Deberes del Hombre, aprobada en abril de 1948, en la Novena Conferencia Panamericana, celebrada en Bogotá ${ }^{79}$, siete meses antes de la Declaración Universal de Derechos

teriores derivaron en la Declaración de Friburgo sobre los derechos culturales, de 2007, que contempla la libertad de desarrollar y compartir conocimientos, como elemento integrante de la participación en la vida cultural.

77 Originalmente dicha Carta formó parte del Tratado por el que se establecía una Constitución para Europa, que hoy tiene naturaleza vinculante en virtud del Tratado de Lisboa, de 13 de diciembre de 2007 y que sustituye dicho instrumento.

${ }^{78}$ Sevilla (2004) Dentro de los antecedentes de esta disposición se consideran, entre otros, el artículo 27 de la Declaración Universal de Derechos Humanos y el artículo 15 del Pacto Internacional de Derechos Económicos, Sociales y Culturales (pp. 487-489).

${ }^{79}$ No fue adoptada en forma de convención, pero ha adquirido enorme importancia a raíz de lo dispuesto en el artículo 1.2 del Estatuto de la Comisión Interamericana de Derechos Humanos, que se remite a aquella y al 
Humanos. Este documento se refiere a la libertad de investigar en un sentido amplio, como un derecho de todos los seres humanos a tener acceso al saber. Su artículo $4^{\circ}$ dispone que "toda persona tiene derecho a la libertad de investigación, de opinión, de expresión y de difusión del pensamiento por cualquier medio".

Dicha disposición es complementada por el artículo 13, según el cual "toda persona tiene el derecho de participar en la vida cultural de la comunidad, gozar de las artes y disfrutar de los beneficios que resulten de los progresos intelectuales y especialmente de los descubrimientos científicos".

Este instrumento interesa porque de conformidad a las normas de interpretación contenidas en el artículo 29, letra d), de la Convención Interamericana, ninguna de sus disposiciones puede ser interpretada en el sentido de "excluir o limitar el efecto que puedan producir la Declaración Americana de Derechos y Deberes del Hombre y otros actos internacionales de la misma naturaleza" 80 .

La misma omisión que se observa en los antes aludidos documentos regionales, se advierte igualmente en la Carta Africana sobre Derechos Humanos y de los Pueblos (Carta de Banjul), de 27 de julio de 1981. Ello priva a la libertad de investigación científica de una adecuada protección internacional, la que los referidos instrumentos dispensan a otros derechos humanos, a través de órganos de jurisdicción supranacional y de procedimientos jurisdiccionales ${ }^{81}$.

Pese a su importancia, las disposiciones que consagran la libertad de investigación científica en instrumentos internacionales, hasta hace poco tiempo no habían recibido mucha atención de parte de las autoridades ni de los teóricos ${ }^{82}$. El artículo 15 del Pacto Internacional de Derechos Económicos, Sociales y Culturales no ha sido objeto de alguna Observación General del Comité de Derechos Económicos, Sociales y Culturales. Asimismo, el artículo 14 del Protocolo Adicional de la Convención de Derechos Humanos no ha sido interpretado por ningún Tribunal ni aplicado por órganos competentes.

Para Asbjørn Eide, la aparentemente poca importancia que se les ha concedido se manifiesta en su ubicación, al final de la lista de derechos en los respectivos textos internacionales, y también se hace patente en la escasa atención que se les presta tanto en la teoría como en la práctica ${ }^{83}$. Hasta hace unos años eran disposiciones poco conocidas y "casi nunca invocadas por la comunidad científica", porque generalmente carecen de eficacia inmediata $^{84}$.

Pacto de San José de Costa Rica al señalar cuáles son los que se entienden como derechos humanos. Mayorga (1996) p. 90.

${ }^{80}$ La Convención Americana se refiere tangencialmente en el artículo 26 a la adopción de providencias por parte de los Estados "...para lograr progresivamente la plena efectividad de los derechos que se derivan de las normas económicas, sociales y sobre educación, ciencia y cultura”, contenidas en la Carta de la OEA.

${ }^{81}$ En los dos primeros Convenios interregionales, los órganos contemplados para tales efectos son la Comisión Interamericana de Derechos Humanos y la Corte Interamericana de Derechos Humanos y la Comisión Europea de Derechos Humanos y el Tribunal Europeo de Derechos Humanos, respectivamente.

${ }^{82}$ JaYAWICKRAMA (2002) p. 906.

${ }^{83}$ EIde (1995) p. 229.

${ }^{84}$ Hondius (1994) p. 198. 
En el plano internacional, la Organización de Naciones Unidas creó un organismo especializado, la Organización de las Naciones Unidas para la Educación, la Ciencia y la Cultura -UNESCO-, cuya actuación se relaciona, entre otros derechos, con la libertad de investigación científica. En su Acta de Constitución, de 16 de noviembre de 1945, se señalan las circunstancias que justificaron su creación, entre ellas, la necesidad de "velar por el pleno e igual acceso a la educación, la posibilidad de investigar libremente la verdad objetiva y el libre intercambio de ideas y conocimientos".

Precisamente de la UNESCO han emanado varios documentos relativos a la libertad de investigación científica, aunque sin carácter vinculante (soft law), entre los cuales cabe destacar dos. En primer lugar, la Recomendación relativa a la situación de los investigadores científicos, adoptada por la Conferencia General de la UNESCO, en la $18^{a}$ reunión, celebrada del 17 de octubre al 23 de noviembre de 1974, en París. En segundo lugar, la "Declaración sobre la Ciencia y la Utilización del Saber Científico" o "Declaración de Budapest”, adoptada junto con el Proyecto de Programa en pro de la Ciencia: Marco General de Acción, en la Conferencia Mundial sobre la Ciencia para el siglo XXI: Un nuevo compromiso, celebrada en Budapest el 1 de julio de 1999, bajo el auspicio de la UNESCO y el Consejo Internacional para la Ciencia, ICSU.

La Recomendación relativa a la situación de los investigadores cientificos se refiere en términos generales a los beneficios, a las amenazas de los descubrimientos científicos y de los adelantos tecnológicos y a las políticas públicas que pueden adoptar los Estados miembros.

La Declaración de Budapest se hace cargo de varios tópicos relacionados con la libertad de investigación científica, como la utilización responsable del saber científico; el aporte de todas las culturas al conocimiento, así como al reconocimiento y protección de los conocimientos tradicionales y la necesidad de que todos los seres humanos accedan a los beneficios de la ciencia. Asimismo, enfatiza el carácter de "bien compartido solidariamente" de la ciencia; resalta la importancia de esta y de la cooperación internacional para la paz y el desarrollo; la necesidad de conciliar la difusión de los conocimientos científicos con la protección de los derechos de propiedad intelectual, etc. En ella se adoptan una serie de compromisos sobre el curso que ha de seguir la ciencia o en el cual sería deseable encauzarla ${ }^{85}$.

En los últimos años, varias declaraciones sin fuerza vinculante han puesto énfasis tanto en la libertad de investigación científica como en los avances científicos y tecnológicos que se han producido en ámbitos de las ciencias de la vida como la genética, la genómica y la biomedicina, cuya finalidad es establecer algunos principios y límites en los temas bioéticos. Son de especial significación los tres documentos aprobados por la UNESCO los años 1997, 2003 y 2005, esto es, la Declaración Universal sobre el Genoma Humano y los Derechos Humanos; la Declaración Internacional sobre Datos Genéticos Humanos y la Declaración Universal sobre Bioética y Derechos Humanos, respectivamente.

La Declaración Universal sobre el Genoma Humano y los Derechos Humanos, de 11 de noviembre de 1997, hecha suya por la Asamblea de las Naciones Unidas el 9 de diciembre de 1998, se refiere a la libertad de investigación científica en la primera parte del artículo

${ }^{85}$ El numeral 1.1 .8 señala que "la investigación científica deberá apoyarse en un marco jurídico apropiado en el plano nacional e internacional, aunque a continuación señala que a este respecto revisten especial importancia la libertad de expresión y la protección de la propiedad intelectual. 
12.b). Esta disposición, después de consignar que "toda persona debe tener acceso a los progresos de la biología, la genética y la medicina en materia de genoma humano", reconoce sus orígenes al señalar que "la libertad de investigación, que es necesaria para el progreso del saber, procede de la libertad de pensamiento”. Más adelante, el artículo 14 de la misma declaración establece que "los Estados tomarán las medidas apropiadas para favorecer las condiciones intelectuales y materiales propicias para el libre ejercicio de las actividades de investigación...” y, en el artículo 15, que "tomarán las medidas apropiadas para fijar el marco del libre ejercicio de las actividades de investigación sobre el genoma humano".

Por su parte, la Declaración Internacional sobre Datos Genéticos Humanos, de 16 de octubre de 2003, destinada a la protección de los datos científicos y datos médicos y personales, especialmente la información genética humana y los datos proteómicos, alude a la libertad de investigación científica tanto en el preámbulo como en el artículo $1^{\circ}$. En el preámbulo reafirma el vínculo entre aquella y las libertades de pensamiento y expresión. El artículo $1^{\circ}$, por su parte, contempla dentro de los objetivos de la Declaración el velar por el respeto a la dignidad humana y la debida protección de los derechos humanos y las libertades fundamentales en la recolección, tratamiento, utilización y conservación de datos genéticos humanos; prestando la "debida consideración a la libertad de pensamiento y de expresión, comprendida la libertad de investigación”.

Finalmente, la Declaración Universal sobre Bioética y Derechos Humanos, aprobada el 19 de octubre de 2005, reconoce en el preámbulo que "gracias a la libertad de la ciencia y de la investigación, los adelantos científicos y tecnológicos han reportado, y pueden reportar, grandes beneficios a la especie humana”. Conforme señala el artículo 1.2, está dirigida a los Estados, aunque también imparte orientación, cuando procede, para las decisiones o prácticas de individuos, grupos, comunidades, instituciones y empresas, públicas y privadas. Entre sus objetivos enuncia, en el artículo 2 letra d), el "reconocer la importancia de la libertad de investigación científica y las repercusiones beneficiosas del desarrollo científico y tecnológico", destacando también que aquella no es un derecho absoluto, ya que es indispensable que la "investigación y los consiguientes adelantos se realicen en el marco de los principios éticos enunciados en esta Declaración y respeten la dignidad humana, los derechos humanos y las libertades fundamentales".

La misma disposición se refiere en la letra f) a los beneficios, señalando que su objetivo consiste en "promover un acceso equitativo a los adelantos de la medicina, la ciencia y la tecnología, así como la más amplia circulación posible y un rápido aprovechamiento compartido de los conocimientos relativos a esos adelantos y de sus correspondientes beneficios, prestando una especial atención a las necesidades de los países en desarrollo" ${ }^{66}$.

De las tres declaraciones aludidas se desprende de manera clara que cuando se refieren a la libertad de investigación científica no aluden a un derecho nuevo, sino a un derecho de antiguo vinculado con las libertades de pensamiento y de expresión, que hoy en día, ha recobrado importancia ante los avances científicos y tecnológicos, que hacen necesario regular su ejercicio.

${ }^{86}$ Sobre este aspecto véase también el artículo 13 de la Carta de Derechos y Deberes Económicos de los Estados, aprobada en la Sesión Plenaria de la Asamblea General de las Naciones Unidas el 12 de diciembre de 1974. 
En lo que respecta al titular de la libertad de investigación científica también se han dictado normas con la finalidad de favorecer a colectivos determinados, como las mujeres y aquellos que por distintas razones han estado excluidos de su ejercicio. En este sentido, destacan algunas normas no vinculantes como la Recomendación relativa a la situación de los investigadores cientificos, de 1974, y la Declaración sobre la Ciencia y el uso del Saber Cientifico, adoptado por la Conferencia Mundial sobre la Ciencia, el 1 de julio de $1999^{87}$.

En lo que respecta al contenido de algunas investigaciones, la Declaración de la Unesco sobre la raza y los prejuicios raciales, de 1978, contiene en el artículo 2.1 una condena a los resultados de las investigaciones de índole racista, disponiendo que "Toda teoría que invoque una superioridad o inferioridad intrínseca de grupos raciales o étnicos que dé a unos derecho a dominar o eliminar a los demás, presuntos inferiores, o que haga juicios de valor basados en una diferencia racial, carece de fundamento científico y es contraria a los principios morales y éticos de la humanidad".

De las normas precedentemente transcritas se pueden extraer algunas conclusiones sobre la evolución que ha experimentado el tratamiento de la libertad de investigación científica en el plano internacional, que según se reconoce en los mismos instrumentos tiene origen en las libertades de pensamiento y expresión.

En un primer momento, interesaba proteger el ámbito de autonomía del titular -la dimensión individual del derecho-, sin desconocer la trascendencia y repercusión social de la actividad científica ni su importancia en el desarrollo y progreso de la sociedad. Después se irá poniendo énfasis en otros aspectos, como la necesidad de priorizar la cooperación y el intercambio entre los Estados para el mejor desarrollo de la actividad científica y la protección de los otros sujetos de la libertad, los destinatarios, amparados por el derecho de acceso a los beneficios de la ciencia.

Desde la segunda mitad del siglo XX y en la primera década del siglo XXI, se ha hecho manifiesto el interés y preocupación de la sociedad en la prevención y manejo de los riesgos de algunos avances científicos en ámbitos específicos como la biotecnología, la genética, la genómica y ciertas aplicaciones en la medicina. Ello se refleja en la progresiva regulación de los diversos aspectos de la actividad científica y especialmente en el establecimiento de límites al ejercicio del derecho que la ampara, lo que progresivamente han comenzado a trasladarse desde el ámbito internacional al orden interno de los Estados.

\section{LA LIBERTAD DE INVESTIGACIÓN CIENTÍFICA EN EL ORDENAMIENTO JURÍDICO CHILENO}

Revisada la forma en que la libertad de investigación científica se recoge en diversos textos constitucionales y en los instrumentos internacionales, corresponde finalmente hacer una breve descripción de las normas que en nuestro ordenamiento jurídico aluden a algunos aspectos de la actividad científica, comenzando por la Constitución Política y siguiendo con las demás normas infraconstitucionales.

${ }^{87}$ Véase los artículos 34 y 42 de la Declaración sobre la Ciencia y el uso del saber científico y el $N^{\circ} 20$.d) de la Recomendación relativa a la situación de los investigadores científicos. 
La Constitución Política de la República de Chile de 1980, al igual que los textos constitucionales que la precedieron, no contempla de manera explícita la libertad de investigación científica. No obstante ello, este derecho puede considerarse tácitamente comprendido y amparado por la libertad de emitir opinión y de informar, consagrada en el artículo $19 \mathrm{~N}^{\circ} 12$ de la Carta Fundamental o protegido por la vía del artículo 5º, inciso segundo, que alude a los derechos garantizados por los tratados internacionales ratificados por Chile y que se encuentran vigentes.

La única mención que la Carta Fundamental hace a la actividad científica se encuentra en el artículo $19 \mathrm{~N}^{\circ} 10$, inciso sexto, que consagra el derecho a la educación, según el cual corresponderá al Estado “...estimular la investigación científica y tecnológica, la creación artística y la protección e incremento del patrimonio cultural de la Nación”. Esta norma contiene un mandato constitucional para los poderes públicos, consistente en el deber de proteger y estimular, entre otras actividades, la investigación científica y tecnológica, sin que esos deberes aparezcan directamente asociados a la libertad de investigación científica.

En nuestro ordenamiento jurídico existen también varias disposiciones legales dispersas que regulan diferentes aspectos concretos de la investigación científica, y que conforman el estatuto jurídico de esta actividad. Sin ánimo exhaustivo, veremos algunos de ellos.

En primer lugar, merece especial mención la ley $N^{\circ} 20.120$, sobre Investigación Científica en el Ser Humano su Genoma, y Prohíbe la Clonación Humana, cuyo reglamento está contenido en el decreto $\mathrm{N}^{\circ} 114$, de 22 de noviembre de 2010, del Ministerio de Salud. El artículo 2 de la referida ley reconoce "la libertad para llevar a cabo actividades de investigación científica biomédica en seres humanos", y también el hecho de que esta "tiene como límite el respeto a los derechos y libertades esenciales que emanan de la naturaleza humana, reconocidos tanto por la Constitución Política de la República como por los tratados internacionales ratificados por Chile y que se encuentren vigentes".

Con la finalidad de proteger a las personas que son sujetos pasivos de la investigación, el referido cuerpo normativo establece algunos límites y prohibiciones específicos que afectan a la investigación científica biomédica y a sus aplicaciones clínicas, tales como la exigencia del consentimiento previo e informado (artículos 9, 11 y 20) y de autorizaciones previas (artículo 10). También establece las prohibiciones de practicar la clonación humana, cualquiera sea el fin perseguido y la técnica utilizada (artículo 5); de destruir embriones humanos para obtener células troncales que den origen a tejidos y órganos (artículo 6) y de patentar un gen y las secuencias totales o parciales de ADN (artículo 8, inciso $1^{\circ}$ ). El reglamento, por su parte, detalla estos límites y se refiere al carácter de reservada que tiene la información genética de un ser humano, lo que se traduce, en este ámbito, en que la recopilación, almacenamiento, tratamiento y difusión del genoma de las personas y de toda otra información relacionada con datos sensibles que emane de la investigación, se ajustará a las disposiciones de la ley 19.628 (artículo 23).

Por otro lado, la ley $\mathrm{N}^{\circ} 20.584$, que regula los derechos y deberes que tienen las personas en relación con acciones vinculadas a su atención en salud, dispone en el artículo 21, que toda persona deberá ser informada y tendrá derecho a elegir su incorporación en cualquier tipo de investigación biomédica, en los términos del cuerpo legal precedentemente aludido, manifestando su voluntad de manera previa, libre, informada, personal y por 
escrito, sin que su decisión pueda significar menoscabo en su atención ni sanción alguna. En el artículo 22, se remite al reglamento que contendrá, entre otras materias, las normas necesarias para la protección de los derechos de las personas respecto de la investigación científica.

El artículo 28, inciso primero, del mismo cuerpo legal, dispone que "ninguna persona con discapacidad psíquica o intelectual que no pueda expresar su voluntad podrá participar en una investigación científica”.

Un límite similar a la libertad de investigación científica se contempla en el artículo 11 de la ley $\mathrm{N}^{\circ}$ 20.422, sobre Discapacidad, que establece una prohibición a favor de la persona con discapacidad mental, al prescribir que en ningún caso aquella "podrá ser sometida, contra su voluntad, a prácticas o terapias que atenten contra su dignidad, derechos o formen parte de experimentos médicos o científicos".

Otro tanto ocurre con la ley $\mathrm{N}^{\circ} 20.380$, sobre Protección de Animales, que dedica los artículos 6 a 10 a la regulación de los experimentos con animales vivos, estableciendo una serie de exigencias para llevar a cabo estas actividades científicas, entre otras, que aquellos deben practicarse por personal calificado y en instalaciones adecuadas, evitando al máximo el padecimiento de los animales, disposiciones que deberán ser complementadas por el correspondiente reglamento.

Por su parte, la ley $\mathrm{N}^{\circ} 18.892$, Ley General de Pesca y Acuicultura, según las modificaciones introducidas por la ley $\mathrm{N}^{\circ} 20.434$, contempla en el artículo $13 \mathrm{~F}$ algunas limitaciones a la acuicultura cuando esta actividad tiene el carácter de experimental, incorporando a nuestro ordenamiento la noción de bienestar animal, que curiosamente, no aparece en la norma más general antes aludida.

El Libro Noveno del Código Sanitario (artículos 145 y siguientes), contenido en el DFL N $\mathrm{N}^{\circ} 725$, de 1968, regula la utilización de cadáveres, o de parte de ellos, con fines científicos o terapéuticos, disposiciones que son complementadas por el reglamento contenido en el D.S. $\mathrm{N}^{\circ} 240$, de 1983.

En el ámbito específico de la educación, la ley $\mathrm{N}^{\circ}$ 20.370, General de Enseñanza -LEGE-, al igual que el artículo $19 \mathrm{~N}^{\circ} 10$ de la Carta Fundamental, alude en el artículo $5^{\circ}$ al deber del Estado de "estimular la investigación científica, tecnológica y la innovación"88. Similar deber de promoción está contemplado en el artículo 18 letra c) de la ley $\mathrm{N}^{\circ} 19.175$, Orgánica Constitucional de Gobierno y Administración Regional, conforme al cual, una de las atribuciones del Gobierno Regional consiste en "promover la investigación científica y tecnológica y preocuparse por el desarrollo de la educación superior y técnica de la región".

Como se dijo, esta actividad impuesta al Estado requiere de los poderes públicos más que la abstención típica de los clásicos derechos liberales, prestaciones o actuaciones que se traduzcan en el otorgamiento de medios materiales que permitan a los particulares el ejercicio de su derecho.

En relación con la faceta prestacional de la libertad de investigación científica, el artículo $6^{\circ}$ de la ley $\mathrm{N}^{\circ} 16.746$, creó la Comisión Nacional de Investigación Científica

${ }^{88}$ De manera similar, la ley anterior $N^{\circ} 18.962$, Orgánica Constitucional de Enseñanza -LOCE- , contemplaba en el artículo $2^{\circ}$, inciso cuarto, el deber del Estado de "estimular la investigación científica y tecnológica". 
y Tecnológica, CONICYT ${ }^{89}$, bajo la forma de corporación autónoma con personalidad jurídica de derecho público, cuyo objeto es asesorar al Presidente de la República en el planeamiento, fomento y desarrollo de las investigaciones en el campo de las ciencias puras y aplicadas $^{90}$.

También merece mención la ley $\mathrm{N}^{\circ}$ 20.241, que establece un incentivo tributario a la inversión privada en investigación y desarrollo, cuyo reglamento está contenido en el Decreto $\mathrm{N}^{\circ}$ 68, de 23 de diciembre de 2009. El incentivo que consagra es de carácter temporal y su finalidad es aumentar la inversión privada en investigación y desarrollo.

Hay otros aspectos complementarios de la libertad de investigación científica que se regulan en la ley $\mathrm{N}^{\circ} 17.336$, sobre Propiedad Intelectual, y en la ley $\mathrm{N}^{\circ} 19.039$, de Propiedad Industrial, cuerpos normativos que contienen normas de protección sobre algunos de los resultados de la investigación científica y se refieren a los derechos de propiedad intelectual y patentes.

En suma, en nuestro ordenamiento jurídico encontramos varias disposiciones legales que regulan diversos aspectos de la libertad de investigación científica, incluso el establecimiento de algunos límites a su ejercicio, sin que este derecho esté contemplado expresamente en la Carta Fundamental, aunque como se dijo, puede considerarse tácitamente amparada por la misma.

\section{CONCLUSIONES}

El panorama que se ha presentado en estas páginas nos permite apreciar cómo la consagración específica de la libertad de investigación científica se ha ido generalizando, de manera progresiva, en los distintos textos constitucionales y en el orden internacional.

A nivel internacional, numerosos instrumentos han reconocido la libertad de investigación científica como un derecho humano. Últimamente, en ellos se ha reflejado también la preocupación global de proteger tanto la libertad como otros derechos que puedan verse afectados, mediante el establecimiento de algunos límites a su ejercicio.

En aquellos ordenamientos en los que no tiene consagración expresa, como el nuestro, la actividad científica se entiende tácitamente amparada por la libertad de expresión -libertad de emitir opinión y de informar, de acuerdo al artículo 19 No 12 de la Constitución Política de la República- o se entiende protegida por la vía del artículo 5, inciso segundo, que alude al deber del Estado de promover los derechos garantizados por los tratados internacionales ratificados por Chile y que se encuentran vigentes, aunque esa protección es insuficiente y suele generar algunos inconvenientes, como los que se señalan a continuación y que aconsejan una regulación expresa.

\footnotetext{
${ }^{89}$ Leyes similares de fomento de la ciencia existen, por ejemplo, en España -actualmente, en proceso de revisión-; México; Colombia, Venezuela, etc.

${ }^{90}$ Esa ley creó, además el Premio Nacional de Ciencia. El Estatuto Orgánico de la CONICYT está contenido en el Decreto $N^{\circ}$ 491, de 26 de febrero de 1991. Por su parte, el DFL N 33, de1981 (Diario Oficial de 27 de octubre de 1981), creó el Fondo de Desarrollo de Ciencia y Tecnología, FONDECYT, destinado a financiar proyectos de investigación científica y tecnológica y que es administrado, entre otros fondos, por la CONICYT.
} 
En primer lugar, si bien en sus orígenes la libertad de investigación científica comparte fundamentos con la libertad de pensamiento, de expresión y la libertad de cátedra y puede considerarse amparada por los mismos, paulatinamente se ha ido singularizando como un derecho específico. La protección que aquellos pueden brindar a la actividad científica es hoy insuficiente, por las particularidades propias de aquella.

En segundo lugar, estamos conscientes de que es necesario delimitar el marco dentro del cual puede legítimamente ejercerse este derecho, lo cual significa, por cierto, que no es un derecho absoluto. Se ha ido generalizando en los distintos ordenamientos jurídicos, la regulación de la actividad científica y el establecimiento de límites, lo que obliga a considerar también la libertad que ampara su ejercicio. Esta incipiente regulación constituye una razón más para una consagración expresa de este derecho en nuestro ordenamiento jurídico, pues debe evitarse que esos límites afecten un derecho cuyo contenido no está prefijado por la Constitución y al que no puede hacerse extensiva la garantía del contenido esencial contenida en el artículo $19 \mathrm{~N}^{\circ} 26$ de la Carta Fundamental.

En tercer lugar, la actividad científica tendría una mayor protección, que vendría dada por las normas de máxima jerarquía dentro del ordenamiento jurídico, lo que redundaría en la certeza acerca de su contenido, pues el haz de facultades que la integran estaría determinado por su formulación constitucional. Además, en el evento de suscitarse un conflicto en que se vea involucrada esta libertad, no sería necesario recurrir a la protección constitucional indirecta.

Finalmente, los avances científicos han puesto en el centro del debate el control de la ciencia y en el orden interno de los Estados se han comenzado a regular algunos aspectos de la investigación científica, como la protección de las personas que intervienen como sujetos pasivos en la investigación, exigiendo la manifestación clara del consentimiento informado y estableciendo normas especiales de protección cuando se trata de menores y personas con discapacidad; el uso racional de los animales en los laboratorios, normas de protección de datos personales, etc. El actual estado de la ciencia y los nuevos desafíos del Derecho frente a esta nueva realidad, sumado al importante papel social que aquella cumple, son razones más que suficientes para que la libertad que ampara su ejercicio tenga consagración constitucional explícita.

\section{BIBLIOGRAFÍA CITADA}

Adalsteinsson, Ragnar y Thorhallson, Páll (1999): “Article 27”, in Eide, Asbjørn and Alfredsson, Gudmundur (Eds.), The Universal Declaration of Human Rights. A Common Standard of Achievement (Netherlands, Martinus Nijhoff Publishers) pp. 575-596.

Alexy, Robert (2002): Teoría de los Derechos Fundamentales (traducción de Ernesto Garzón Valdés, Madrid, Centro de Estudios Constitucionales) 607 pp.

Ansuátegui Roig, Francisco Javier (1994): Orígenes doctrinales de la libertad de expresión (Madrid, Universidad Carlos III de Madrid-Boletín Oficial del Estado) 479 pp.

Barceló I Serramalera, Mercé (2004): “Las libertades de expresión”, en Balaguer CALlejón, Francisco (Coord.), Derecho Constitucional y Cultura. Estudios en Homenaje a Peter Häberle (Madrid, Tecnos) pp. 565-604. 
Bellver Capella, Vicente (1999): "Bioética y Constitución”, Claves de Razón Práctica, N 91: pp. 67-70.

Benda, Ernesto (2001): "Dignidad humana y derechos de la personalidad", en VV.AA., Manual de Derecho Constitucional (traducción de Antonio López Pina, Barcelona, Marcial Pons, 2a edición) pp. 117-144.

Bernal, John D. (1989): Historia Social de la Ciencia. Vol. 1, La ciencia en la historia (traducción de Juan Ramón Capella, Barcelona, Ediciones Península, 6a edición) 540 pp.

Broncano, Fernando (2001): “¿Es la ciencia un bien público?”, Claves de Razón Práctica $\mathrm{N}^{\circ}$ 115: pp. 22-28.

Bunge, Mario (1988): "La ciencia básica es inocente, pero la ciencia aplicada y la técnica pueden ser culpables", Conferencias de la Universidad Internacional de la Axarquía, $\mathrm{N}^{\circ} 1$, (sin mención de ciudad, Amigos de la Cultura Científica) 23 pp.

Bunge, Mario (1979): La investigación cientifica. Su estrategia y su filosofía (traducción de Manuel Sacristán, Barcelona, Ariel, primera reimpresión de la segunda edición corregida) 955 pp.

Carro, José Luis (1977), "Libertad científica y organización universitaria”, Revista Española de Derecho Administrativo, $\mathrm{N}^{\circ}$ 13: pp. 211-227.

Cortina, Adela, (2004): "Fundamentos filosóficos del principio de precaución”, en ROMEO Casabona, Carlos María (Ed.), Principio de Precaución, Biotecnología y Derecho, (Bilbao-Granada, Comares-Cátedra Interuniversitaria Fundación BBVA-Diputación Foral de Bizkaia de Derecho y Genoma Humano) pp. 3-16.

Cossio Díaz, José Ramón (1989): Estado Social y derechos de prestación (Madrid, Centro de Estudios Constitucionales) 294 pp.

Cueto Pérez, Miriam (2002): Régimen Jurídico de la Investigación Científica. La labor investigadora de la universidad (Barcelona, Cedecs Editorial) $288 \mathrm{pp}$.

Cumplido, Francisco (2005): "Constitución y visión prospectiva", en Nogueira Alcalá, Humberto (Coord.), La Constitución Reformada de 2005 (Santiago, Centro de Estudios Constitucionales Universidad de Talca, LOM) pp. 571-578.

Chalmers, Alan F. (2000): ¿Qué es esa cosa llamada ciencia?: Una valoración de la naturaleza y el estatuto de la ciencia y sus métodos (Madrid, Siglo Veintiuno, $3^{\text {a }}$ edición corregida y aumentada) $245 \mathrm{pp}$.

Chueca Rodríguez, Ricardo (2008): "El derecho fundamental a la investigación científica”, REDUR, N 6: pp. 5-15.

De Carreras, Francesc (1991): "La libertad de expresión: un derecho constitucional", en Freixes, Teresa (Coord.), Libertad de expresión, Anuario 1990, 1a edición, Universidad Autónoma de Barcelona, pp. 11-35.

De Lora, Pablo; Gascón, Marina (2008): Bioética. Principios, Desafíos y Debates (Madrid, Alianza Editorial) 349 pp.

Delgado, Richard y Millen, David R. (1977-1978), “God, Galileo and Government: Toward Constitutional Protection for Scientific Inquiry", en Washington Law Review, No 53: pp. 349-404. 
Echeverría, Javier (2001), “Tecnociencia y sistema de valores”, en López Cerezo, José A. y Sánchez Ron, José M. (Eds.), Ciencia, tecnología, sociedad y cultura en el cambio de siglo (Madrid, Biblioteca Nueva-Organización de Estados Iberoamericanos), pp. 221-230.

EIde, Asbjørn (1995): “Cultural Rights as Individual Human Rights”, in Eide, Asbjørn; Krause, Catarina, and Rosas, Allan (1995), Economic, Social and Cultural Rights (Dordrecht/Boston/London, Martinus Nijhoff Publishers) pp. 229-240.

Emerson, Thomas I. (1976-1977): "Colonial Intentions and Currents Realities of the First Amendment", University of Pennsylvania Law Review, N 125, 1976-1977: pp. 737-760.

Eser, Albin, (1987): “The researcher as 'offender' and 'victim'. Comparative Observations as to Freedom and Responsibility of Science and Technology", en Brigham Young University Law Review, Issue 2: pp. 571-585.

Esteve Pardo, José (2008): "En el ocaso del paradigma Galileo. El nuevo y desatendido entorno de la libertad de investigación científica", en Martín Rebollo, Luis (dir.), Derechos Fundamentales y otros estudios en homenaje al profesor Dr. Lorenzo Martin-Retortillo, Vol. II (Zaragoza; Isac Artes Gráficas-Facultad de Derecho Universidad de Zaragoza) pp.1613-1633.

Ferguson, James R. (1978-1979): "Scientific Inquiry and the First Amendment", Cornell Law Review N 6: pp. 639-665.

Fernández-Miranda y Campoamor, Alfonso y García Sanz, Rosa María (1984), "Artículo 20. Libertad de expresión y derecho de la información”, en Álzaga Villaamil, Óscar (Dir.), Comentarios a las leyes políticas. Constitución española de 1978 (Madrid, Edersa) pp. 489-554.

Fernández Segado, Francisco (1992): El Sistema Constitucional Español (Madrid, Dykinson) $1140 \mathrm{pp}$.

Gallilei, Galileo (1994): Carta a Cristina de Lorena, primera reimpresión (Madrid, Alianza Editorial) 128 pp.

García Fernández, Javier (1996): “Artículo 44.2. Fomento de la ciencia”, en Alzaga Villaamil, Óscar (Dir.), Comentarios a la Constitución Española de 1978, Tomo IV, Artículos 39 a 55 (Madrid, Edersa) pp. 205-216.

Garín, Eugenio (1982): Ciencia y vida civil en el renacimiento italiano (Madrid, Taurus) $175 \mathrm{pp}$.

Gómez Diez, Justo, (1995): "La propiedad intelectual y el artículo 20.1.b) de la Constitución española", Revista de la Facultad de Derecho de la Universidad Complutense, $\mathrm{N}^{\circ}$ 84: pp.165-190.

Gómez SÁnchez, Yolanda (2007): "La libertad de creación y producción científica en la ley de investigación científica: Objeto, ámbito de aplicación y principios generales de la ley”, en Sánchez-Caro, Javier y Abellán, Fernando (Coords.), Investigación biomédica en España: Aspectos Bioéticos, Jurídicos y Cientificos (Granada, Comares) pp. 1-52.

GonzÁlez, Juliana (1999): "Valores éticos de la ciencia", en VÁsquez, Rodolfo (Comp.), Bioética y Derecho. Fundamentos y problemas actuales (México D.F., Instituto Tecnológico Autónomo de México-Fondo de Cultura Económica) pp. 25-41. 
González García, Marta I., López Cerezo, José A. y Luján López, José 1. (1996): Ciencia, tecnología y sociedad. Una introducción al estudio social de la ciencia y la tecnología (Madrid, Tecnos) $336 \mathrm{pp}$.

Gros Espiell, Héctor (1998): “Constitución y Bioética”, en Romeo Casabona, Carlos María (Coord.), Derecho Biomédico y Bioético (Granada, Editorial Comares) pp. 137150.

Hondius, Fritz W. (1994): "La libertad humana y el genoma humano", en El Derecho ante el Proyecto Genoma Humano, Vol. 1. (Madrid, U. de Deusto-Excma. Diputación de Bizkaia-Fundación BBV) pp. 181-189.

Jayawicjrama, Nihal (2002): The Judicial Application of Human Rights Law. National, Regional and International Jurisprudence (Oxford, Oxford University Press) 965 pp.

Jimena Quesada, Luis (1995): "La protección de los derechos económicos, sociales y culturales”, en Cosani, Norberto E. (Dir.), La protección universal y regional de los derechos humanos (La Plata, Universidad Nacional de la Plata) pp. 65-86.

Jonas, Hans (1997): Técnica, medicina y ética. La práctica del principio de responsabilidad (traducción de Carlos Fortea Gil, Barcelona, Paidós) 206 pp.

Knoepffler, Nikolaus y Dettweiler, Ulrich (2002): "Human Experimentation. Legal Regulation and Ethical Justification in Germany", en Revista de Derecho y Genoma Humano, $\mathrm{N}^{\circ} 17$ : pp. 57-74.

Liz, Manuel (1995): "Conocer y actuar a través de la tecnología”, en Broncano, Fernando (Ed.) Nuevas meditaciones sobre la técnica (Madrid, Editorial Trotta) pp. 23-51.

Lucas Verdú, Pablo (1981): voz "libertad de cátedra”, en Nueva Enciclopedia Jurídica, Tomo XV (Barcelona, F. Seix Editor) pp. 340-345.

Martínez Val, José Ma (1988): "La libertad de investigación en genética humana y sus límites", Revista General de Derecho, año XLIV, N 523: pp. 2495-2505.

Mayorga Lorca, Roberto (1996): Naturaleza Jurídica de los Derechos Económicos, Sociales y Culturales (Santiago, Editorial Jurídica de Chile, segunda edición) 233 pp.

Mirkine-Guetzevich, Boris (1931): Las Nuevas Constituciones del Mundo (Madrid, Editorial España) 713 pp.

Nash Rojas, Claudio (2005): "Derechos fundamentales. La reforma pendiente en la Constitución de 1980”, Revista de Derecho. Universidad de Concepción, Nº. 217-218, pp. 119-146.

Navarro Beltrán, Enrique (2009): “30 años del recurso de protección, en VVAA, Temas Actuales de Derecho Constitucional. Libro homenaje al Profesor Mario Verdugo Marinkovic (Santiago, Editorial Jurídica de Chile-Asociación Chilena de Derecho Constitucional) pp. 141-154.

Núñez de Castro, Ignacio (2000): “Investigación”, en Cortina, Adela y Conill, Jesús (Dir.), 10 palabras clave en ética de las profesiones (Navarra, Editorial Verbo Divino) pp. 153-173.

Nogueira Alcalá, Humberto (2007): "La dignidad humana, los derechos fundamentales, el bloque constitucional de derechos fundamentales y sus garantías jurisdiccionales", Gaceta Jurídica, No 322: pp. 32-67. 
Palombella, Gianluigi (2006): La autoridad de los derechos. Los derechos entre instituciones y normas (traducción de José Calvo González y Cristina Monereo Atienza, Madrid, Editorial Trotta) $191 \mathrm{pp}$.

Peces-Barba Martínez, Gregorio (1994): "La libertad del hombre y el genoma”, en Derechos y Libertades. Revista del Instituto Bartolomé de Las Casas, No 2: pp. 317-335.

Peces-Barba Martínez, Gregorio (1999): Curso de Derechos Fundamentales. Teoría General (Madrid, Universidad Carlos III de Madrid-Boletín Oficial del Estado) 720 pp.

Peces-Barba Martínez, Gregorio (2002): Prólogo, en Pelayo González-Torre, Ángel, Bioética y experimentación con seres humanos (Granada, Editorial Comares) pp. XI-XIII.

Pelayo GonzÁlez-Torre, Ángel (2002): "Investigación científica”, en Romeo Casabona, Carlos María (ed.), El Convenio de Derechos Humanos y Biomedicina. Su entrada en vigor en el ordenamiento jurídico español (Bilbao-Granada, Editorial Comares) pp. 233-255.

Pizzorusso, Alejandro (1981): Lecciones de Derecho Constitucional, Vol. I (traducción de Javier Jiménez Campos, Madrid, Centro de Estudios Constitucionales) 382 pp.

Plaza Penadés, Javier (1997): El derecho de autor y su protección en el artículo 20.1.b) de la Constitución española (Valencia, Tirant lo Blanch) 398 pp.

Polakiewicz, Jörg (1993): "El proceso histórico de la implantación de los derechos fundamentales en Alemania", en Revista de Estudios Políticos, No 81: pp. 23-45.

Prieto SANChÍs, Luis (1989): Estudios sobre Derechos Fundamentales (Madrid, Editorial Debate) $267 \mathrm{pp}$.

RAmírez Briceño, Edgard Roy (1987): La responsabilidad ética en ciencia y tecnología (Cartago, Editorial Tecnológica de Costa Rica) 102 pp.

Rodríguez-Drincourt Álvarez, Juan (2002): Genoma humano y Constitución (Madrid, Civitas) 176 pp.

Romeo Casabona, Carlos María (1996): "Protección de bienes jurídicos e intervención en el genoma humano", en Borrillo, Daniel, Genes en el estrado. Limites jurídicos e implicaciones sociales del desarrollo de la genética humana (Madrid, Consejo Superior de Investigaciones Científicas, Instituto de Estudios Sociales Avanzados) pp. 131-165.

Romeo Casabona, Carlos María (2002): (Ed.), El Convenio de Derechos Humanos y Biomedicina. Su entrada en vigor en el ordenamiento jurídico español (Bilbao-Granada, Editorial Comares) 568 pp.

Romep Casabona, Carlos María (2003): “Los desafíos jurídicos de las biotecnologías en el umbral del siglo veintiuno, en Martínez Morán, Narciso (Coord.), Biotecnología, Derecho y Dignidad Humana (Granada, Editorial Comares) pp. 45-82.

Ruiz-Rico, Gerardo; Pérez Sola Nicolás (2002): "El derecho de acceso a la cultura. El derecho al desarrollo científico", en Monereo, José Luis (Dir.), Comentarios a la Constitución socio-económica de España (Granada, Comares) pp. 1607-1636.

Ruíz Vadillo, Enrique (1986): "La investigación científica y el Derecho. Especial consideración de la ingeniería genética", en Revista General del Derecho, $N^{\circ}$ 504: pp. 36453666.

Sánchez-Caro, Javier (2007): "Principios de la investigación biomédica, con especial referencia a las investigaciones que implican procedimientos invasivos en seres humanos", 
en Sánchez-Caro, Javier y Abellán, Fernando (Coord.), Investigación biomédica en España; Aspectos Bioéticos, Jurídicos y Científicos (Granada, Comares) pp. 53-89.

Sánchez Ferriz, Remedio y García Soriano, María Vicenta (2002): Suiza. Sistema Político y Constitución (Madrid, Centro de Estudios Políticos y Constitucionales) 203 pp.

Sevilla Merino, Julia (2004): "Libertad de las artes y las ciencias", en Álvarez Conde, Enrique y Garrido Mayol, Vicente (Coord.), Comentarios a la Constitución Europea. Libro II. Los Derechos y Libertades (Valencia, Tirant lo Blanch) pp. 481-506.

Scheneider, Hans Peter (1979): "Peculiaridad y función de los derechos fundamentales en el Estado constitucional democrático", en Revista de Estudios Políticos, N 7, Nueva Época: pp. 7-35

Shiva, Vandana, (2003): ¿Proteger o expoliar? Los derechos de propiedad intelectual (traducción de Ana María Cadarso, Barcelona, Intermón Oxfam) 144 pp.

Stetten, Dewitt Jr. (1975): “Freedom of Enquiry”, en Genetics, No 81: pp. 415-425.

Torres del Moral, Antonio (1984): "Artículo 44. Derecho a la cultura y fomento de la ciencia”, en Alzaga Villaamil, Óscar (Dir.), Comentarios a las Leyes Políticas, Tomo IV. Artículos 39 a 55 (Madrid, Edersa) pp. 197-237.

Vega Encabo, Jesús (2001): “Ciencia privada, conocimiento público", en Isegoría, № 25 : pp. 247-252.

Verdugo, Mario; Nogueira, Humberto y Pfeifer, Emilio (2002): Derecho Constitucional, Tomo I (Santiago, Editorial Jurídica de Chile) 569 pp.

Vidal Prado, Carlos (2001): La libertad de cátedra: Un estudio comparado (Madrid, Centro de Estudios Políticos y Constitucionales) 310 pp.

Vivanco Martínez, Ángela (2006): Curso de Derecho Constitucional, Tomo II (Santiago, Pontificia Universidad Católica de Chile) 555 pp.

Zúñiga Urbina, Francisco (2005): "Reforma Constitucional. Presente y Futuro", en Nogueira Alcalá Nogueira, Humberto (Coord.), La Constitución Reformada de 2005 (Santiago, Centro de Estudios Constitucionales, U. de Talca- LOM) pp. 557-569.

\section{NORMAS CITADAS}

Constitución Política de la República de Chile. Texto refundido, coordinado y sistematizado por el Dto. No 100, Diario Oficial de 22 de septiembre de 2005, especialmente artículo $19 \mathrm{~N}^{\circ}$ s. 10 y 12 .

Código Sanitario.

Reglamento del Libro Noveno del Código Sanitario, contenido en el D.S. $N^{\circ} 240$, de 1983. Diario Oficial, 3 de diciembre de 1983.

Ley $N^{\circ}$ 16.746, creó la Comisión Nacional de Investigación Científica y Tecnológica, CONICYT. Diario Oficial, 14 de febrero de 1968.

Ley $\mathrm{N}^{\circ}$ 17.336, sobre Propiedad Intelectual ley $\mathrm{N}^{\circ} 17.336$, sobre Propiedad Intelectual. Diario Oficial, 2 de octubre de 1990.

Ley N 19.039, de Propiedad Industrial. Diario Oficial, 25 de enero de 1991. 
Ley $\mathrm{N}^{\circ} 19.742$, reforma constitucional que elimina la censura cinematográfica sustituyéndola por un sistema de calificación y que consagra el derecho a la libre creación artística. Diario Oficial, 25 de agosto de 2001.

Ley $\mathrm{N}^{\circ}$ 20.120, sobre la investigación científica en el ser humano, su genoma y prohibición de la clonación humana. Diario Oficial, 22 de septiembre de 2006.

Decreto $\mathrm{N}^{\circ} 114$, de 22 de noviembre de 2010, del Ministerio de Salud, que aprueba reglamento de la ley $\mathrm{N}^{\circ} 20.120$, sobre la investigación científica en el ser humano, su genoma, y prohíbe clonación humana. Diario Oficial, 19 de noviembre de 2011.

Ley $\mathrm{N}^{\circ} 20.241$, establece un incentivo tributario a la inversión privada en investigación y desarrollo. Diario Oficial, 19 de enero de 2008.

Ley N ${ }^{\circ}$ 20.370, General de Enseñanza. Diario Oficial, 12 de septiembre de 2009.

Ley $\mathrm{N}^{\circ}$ 20.380, sobre protección de los animales. Diario Oficial, 3 de octubre de 2009.

Ley $\mathrm{N}^{\circ}$ 20.422, sobre Discapacidad. Diario Oficial, 10 de febrero de 2010.

Ley $\mathrm{N}^{\circ} 20.584$, que regula los derechos y deberes que tienen las personas en relación con acciones vinculadas a su atención en salud. Diario Oficial, 24 de abril de 2012.

\section{OTRAS FUENTES}

Historia de la ley $N^{\circ}$ 19.742. Mensaje del Ejecutivo $\mathrm{N}^{\circ} 339 / 334$, de 14 de agosto de 1974 . Disponible en http://www.leychile.cl/Navegar?idNorma=188827\&buscar=19742. [Consultado en enero de 2011]

Comité de Derechos Económicos, Sociales y Culturales. Observación General No 17, de 21 de noviembre de 2005, apartado 2, párrafo 9. E/C.12/GC/17. Disponible en http://portal. unesco.org/culture/es/files/30545/11432108781Comment_sp.pdf/Comment_sp.pdf.

Actas Oficiales de la Comisión de Estudios de la Nueva Constitución. Disponible en http:// www.bcn.cl/lc/cpolitica/actas_oficiales-r [Consultado en octubre de 2011]. 